

Critical Reviews in Food Science and Nutrition

ISSN: 1040-8398 (Print) 1549-7852 (Online) Journal homepage: http://www.tandfonline.com/loi/bfsn20

\title{
Influence of enzymes and technology on virgin olive oil composition
}

\section{Fátima Peres, Luisa L. Martins \& Suzana Ferreira-Dias}

To cite this article: Fátima Peres, Luisa L. Martins \& Suzana Ferreira-Dias (2017) Influence of enzymes and technology on virgin olive oil composition, Critical Reviews in Food Science and Nutrition, 57:14, 3104-3126, DOI: 10.1080/10408398.2015.1092107

To link to this article: https://doi.org/10.1080/10408398.2015.1092107

Accepted author version posted online: 14

Oct 2015.

Published online: 14 Oct 2015.



Џ Article views: 301

View Crossmark data ¿

Citing articles: 3 View citing articles $\square$ 


\title{
Influence of enzymes and technology on virgin olive oil composition
}

\author{
Fátima Peres ${ }^{a}$, Luisa L. Martins ${ }^{b}$, and Suzana Ferreira-Dias ${ }^{b}$

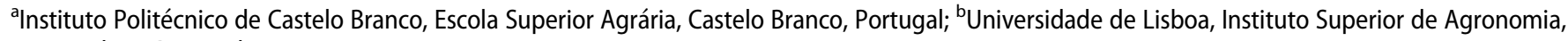 \\ LEAF, Lisbon, Portugal
}

\begin{abstract}
This work aims at presenting the state-of-the-art about the influence of the activity of olive endogenous enzymes, as well as of the application of adjuvants in olive oil technology, discussing their influence on the composition of virgin olive oil, especially in phenols and volatile compounds.

Abbreviations: ADH: Alcohol dehydrogenase; AAT: Alcohol acetyl transferase; 3,4-DHPEA: 3,4-Dihydroxy-PhenylEthanol (hydroxytyrosol); 3,4-DHPEA-EDA: 3,4-Dihydroxy-Phenyl-Ethanol-Elenolic Acid Di-Aldehyde;(oleacein) or dialdehydic form of elenolic acid linked to hydroxytyrosol; 3,4-DHPEA-EA: 3,4-Dihydroxy-Phenyl-Ethanol-Elenolic Acid; oleuropein aglycone; EVOO: Extra Virgin Olive Oil; FAEE: Fatty acids ethyl esters; HPL: Hydroperoxide lyase; LOX: Lipoxygenases; POD: Peroxidases; PPO: Polyphenol oxidase; VOO: Virgin olive oil
\end{abstract}

\section{KEYWORDS}

Adjuvants; oxidoreductases; hydrolases; malaxation; phenols; volatile compounds

\section{Introduction}

The world production of olive oil accounted for 2.4 million tons in 2014, whereas world consumption represents about 3.0 million tons per year (International Olive Council, IOC, 2014). Olive groves account for close to 5 million hectares in the European Union (EU), representing about 1.9 million farms with olive groves. Olive oil production in the EU represents around $73 \%$ of world production. Spain, Italy, and Greece account for about $97 \%$ of EU olive oil production, with Spain producing approximately $62 \%$ of this amount (EC, 2012). The proportion of groves located in disadvantaged zones (mountainous areas and areas with specific disadvantages) is significant, representing $88 \%$ of total area in Portugal. In terms of oil quality, in 2009 Spain produced 35\% of extra virgin oil, 32\% of virgin oil, and $33 \%$ of lampante oil. The respective figures for Italy in relation to these three categories of oil are 59,18 , and $24 \%$, respectively. Consumption models differ in the EU's three main producer countries. In Italy and Greece, the majority of oil consumed is extra virgin, whereas in Spain this category represents less than half of the consumption (EC, 2012). However, the general trend is towards the consumption of extra virgin olive oils (EVOO). This trend is based on the general perception of the consumers that extra virgin olive oil category is the best one in terms of health benefits. Also, its sensory properties reflect the sensory character of each monocultivar or blend of cultivars of olives of origin. The presence in olive oil of minor components with antioxidant potential, as well as its high content in monounsaturated fatty acids appear to be essential for the beneficial effect of this food (Trichopoulou and Dilis, 2007). Thus, sensory properties and health characteristics of olive oil are linked to its chemical characteristics, in particular to the presence of several minor components, which are strongly influenced by the operational conditions in the technological extraction process. Therefore, they may be considered as analytical markers of the quality of olive oil processing.

Olive characteristics are probably the key factor that influences the final virgin olive oil (VOO) quality. The chemical and biochemical properties of the fruits rely on some agronomic practices and several studies point out their effect on minor components of VOO. Cultivar, ripening stage, edapho-climatic conditions and irrigation management are some of the factors that can influence the behavior of the enzymes present in olive pulp and seeds (Angerosa et al., 2000; Aparicio and Luna, 2002; Berenguer et al., 2006; Perez et al., 2014; Servili et al., 2004). Under adequate extraction conditions, extra virgin olive oils are always produced when healthy olives are used, whichever the olive cultivar processed. Only olives attacked by pests and diseases, or fallen to the ground before harvesting, produce olive oils with off-flavors. Other defective sensory notes in VOO are due to inadequate harvesting, postharvesting, processing or oil storage (Alba et al., 2008).

Moreover, the production of high-quality VOO at the highest yield and minimum cost, as well as using an environmentally friendly olive oil production, is more and more requested (García-González and Aparicio, 2010). Consequently, since 1992, the use of "ecological" technologies (two phase decanter) had the greatest impact in the characteristics of VOO, in the last 25 years.

Although this great progress in olive oil technology, the quality of the obtained oil and the extraction yield are still to be optimized, producing an important economic loss for the oil sector (Chiacchierini et al., 2007). Considering the

CONTACT Suzana Ferreira-Dias suzanafdias@mail.telepac.pt E Universidade de Lisboa, Instituto Superior de Agronomia, LEAF, Tapada da Ajuda, 1349-017 Lisbon, Portugal.

Color versions of one or more of the figures in the article can be found online at www.tandfonline.com/bfsn.

○ 2017 Taylor \& Francis Group, LLC 
ecosustainability and lower environmental impact of enzymes, the use of biotechnology in olive oil industry, has also been studied for several years (Alba et al., 1990; Alba-Mendoza et al., 1987; Aliakbarian et al., 2008; Chih et al., 2012; Duarte-Costa and Sameiro, 1978; Ranalli and De Mattia, 1997; Ranalli et al., 2005). The use of several inert processing aids, as well, has been tested to increase olive oil extraction yield (Caponio et al., 2014a; Cert et al., 1996; Moya et al., 2010; Peres et al., 2014).

The enzymatic activities of olives, and consequently the nutritional and the sensory quality of the product, depend on the technological conditions. The changes in VOO characteristics mainly occur in phenol and volatile compounds, which influence decisively VOO nutritional and sensory characteristics (Angerosa, 2000; Clodoveo et al., 2014).

The extraction of olive oil has three main steps: preparation of the paste (crushing and malaxation), solid-liquid and liquidliquid separations. For every extraction process (solid-liquid separation type), the factors that can be changed are: temperature, time, adjuvants, amount of processing water, and oxygen.

The aim of this work is to present the state-of-the-art about the influence of the activity of olive endogenous enzymes, as well as of the application of adjuvants in olive oil industry, discussing their influence on chemical and sensory characteristics of VOO.

\section{Main olive enzymes involved in olive oil extraction process}

In order to evaluate the need for using processing aids in VOO industry, the knowledge of how endogenous enzymes of olive fruits act during ripening, as well as along the extraction process, should be an important information to better control the physical parameters that influence the activity of those enzymes (Clodoveo et al., 2014).

The olive fruit is a drupe and its components are the exocarp or skin, the mesocarp or pulp, and the endocarp or pit, which consists of a woody shell enclosing one or two seeds. Olives contain several enzyme complexes, distributed differently in several parts of the fruits, like pectinases, lipases, lipoxygenases, glycosidases, peroxidases and polyphenol oxidases, among others, that have been extensively studied (García-Rodríguez et al., 2011; Mínguez-Mosquera et al., 2002; Panzanaro et al., 2010; Romero-Segura et al., 2012; Salas et al., 1999; SánchezOrtiz et al., 2011; Taticchi et al., 2013).

It is well known the role of enzymes in food processing and in the decrease of the quality of postharvest of fruits. However, in the case of olive fruits this effect has been scarcely studied and very little is known about the complexity of the enzyme composition of the fruits and their influence on the quality of olive oil. However, it is believed that the different types of the existing enzymes, the content and specific activity in the different parts of the fruit may explain some aspects of olive oil technology.

\section{Oxidoreductases}

Oxidoreductases catalyze oxidation-reduction reactions that can play an important role in taste, flavor and nutritional value of VOO.

These enzymes catalyze oxidation-reduction reactions in which hydrogen or oxygen atoms or electrons are transferred between molecules, and are classified depending on the substrate they act (Ramírez et al., 2003). This class includes lipoxygenases, polyphenol oxidases, and peroxidases, among others.

\section{Lipoxygenases}

Plant lipoxygenases (LOX) are a class of widespread dioxygenases catalyzing the hydroperoxidation of polyunsaturated fatty acids.

LOX (EC 1.13.11.12) catalyzes the oxidation of fatty acids containing cis,cis-1,4-pentadiene groups to produce the corresponding conjugated unsaturated hydroperoxides, which are the precursors of important volatile compounds of olive oil (Williams and Harwood, 2000). Therefore, the preferred substrates of LOX are linoleic and linolenic acids while oleic acid is not oxidized (Belitz et al., 2009). LOX is also capable of use a relatively broad range of other compounds as substrate like carotenoids and polyphenols (Laane et al., 2003).

LOX is a metal-bound protein with a nonheme Fe-atom in its active center; the enzyme is activated by its products and during activation $\mathrm{Fe}^{2+}$ is oxidized to $\mathrm{Fe}^{3+}$. According to Belitz et al. (2009), the catalyzed oxidation pathway is assumed to have the following reaction steps:

(a) Abstraction of a methylene hydrogen atom from the substrate's 1,4-pentadiene system and oxidation of the hydrogen atom to a proton;

(b) The pentadienyl radical bound to the enzyme is then rearranged into a conjugated diene system, followed by the uptake of oxygen;

(c) The peroxy radical formed is then reduced by the enzyme and, after attachment of a proton, the hydroperoxide formed is released.

Lipoxygenases from plants mostly exhibit 9- or 13-regiospecificity. Furthermore, regiospecificity studies indicated that the olive lipoxygenase is a 13-LOX, with the preferential production of $13(\mathrm{~S})-\mathrm{ZE}(\mathrm{Z})$-isomers of fatty acid hydroperoxides (80\%) (Salas et al., 2000). This specificity data is in good agreement with the composition of olive oil volatiles, in which C6 unsaturated aldehydes and alcohols predominate, these being produced from 13 hydroperoxylinolenic acid (Morales et al., 1995).

Two LOX cDNA clones, Oep1LOX2 and Oep2LOX2, have been isolated from olive (Olea europaea cv. Picual). Expression levels of both genes were measured in the mesocarp and seeds during development and ripening of Picual and Arbequina olive fruit and linolenic acid proved to be the preferred substrate; analyses of reaction products showed that both enzymes produce primarily 13-hydroperoxides from linoleic and linolenic acids (Padilla et al., 2009).

Lipoxygenase activity has been detected in olive mesocarp (Salas et al., 1999) and also in oil bodies extracted from olive endosperms (Georgalaki et al., 1998). LOX activity is higher in seeds (Servili et al., 2007) (Table 1).

Maximum LOX activity was found in cvs. Kalamata, Ascolana Tenera, and FS17 at pH 6.0, using linoleic acid as substrate; the maximum LOX activity was measured at $30^{\circ} \mathrm{C}$ (Lorenzi et al., 2006; Ridolfi et al., 2002). Salas et al. (2000) reported that olive LOX is localized in chloroplasts, thylakoids, and microsomes and that the optimum $\mathrm{pH}$ is 5 . 
Table 1. LOX activity found in olives and olive oils (substrate linoleic acid).

\begin{tabular}{llll}
\hline Fruit/VOO & Cultivar & \multicolumn{1}{c}{ LOX activity } & \multicolumn{1}{c}{ Reference } \\
\hline Pulp & FS17 & $833.4 \mathrm{U} \mathrm{mg}^{-1}$ protein & Ridolfi et al. (2002) \\
Pulp & Frantoio & $2.26 \mathrm{U} \mathrm{mg}^{-1} \mathrm{DW}$ & Servili et al. (2007) \\
Seed & & $6.01 \mathrm{U} \mathrm{mg}^{-1} \mathrm{DW}$ & \\
Pulp & Coratina & $2.67 \mathrm{U} \mathrm{mg}^{-1} \mathrm{DW}$ & Servili et al. (2007) \\
Seed & & $7.16 \mathrm{U} \mathrm{mg}^{-1} \mathrm{DW}$ & \\
Olive oil & & $0.11-1.68 \mathrm{U} \mathrm{mg}^{-1}$ protein & Georgalaki et al. (1998) \\
\hline
\end{tabular}

The high levels of LOX activity detected at early stages of fruit development suggest that in olives, as in other plants, this enzyme is important in the physiological response to stress. A steady decrease of LOX activity was observed at more advanced stages of maturation, from 25 to 35 weeks after anthesis, when the fruits are normally harvested for oil extraction (Salas et al., 1999). In early ripening stages, with Cobrançosa olives from irrigated and rain fed orchards, it was not possible to establish any trend in LOX activity measured in fruit mesocarp (Table 2).

The widespread presence of the C6- and C9-aldehydes shows that enzymatic-oxidative cleavage of linoleic and linolenic acids by the enzymes lipoxygenase, hydroperoxide-lyase and, if necessary, an aldehyde-isomerase, generally contributes to the formation of aroma in several foods (Belitz et al., 2009). Along the olive oil extraction, the lipoxygenase pathway is very active during the steps of preparation of paste, i.e., crushing and malaxation. Thus, the aroma of the final VOO will be a function of the activity levels and characteristics of the enzymes involved in LOX pathway (Angerosa et al., 2004; Salas et al., 2000). Figure 1 shows a scheme of the LOX pathway with its three different branches for the production of volatiles.

The branch coming from linoleic acid gave rise to hexanal, hexan-1-ol, and hexyl acetate; the former and the latter were responsible for desirable perceptions. This branch could be seen as the green-sweet aspect of the global green flavor. The second branch could be responsible for the main green notes perception, giving rise to cis-3-hexenal, cis-3-hexen-1-ol, and cis-3-hexenyl acetate. The third branch (trans-2-hexenal and trans-2-hexen-1-ol) could be considered as the bitter-astringent aspect of the green sensory perceptions (Morales et al., 1999).

Thus, analysis of volatile fractions from virgin olive oils by GCxGC-ToFMS showed that virgin olive oil odorants consist
Table 2. LOX activity (substrate linoleic acid) in 'Cobrançosa' mesocarp in early ripening stages in two years and in two olive groves (RF-rain fed; IR-irrigated) in Beira Baixa region, Portugal.

\begin{tabular}{lcccc}
\hline & & \multicolumn{3}{c}{ LOX activity $\left(\mathrm{Ug}^{-1} \mathrm{FW}\right)$} \\
\cline { 3 - 5 } Year & Olive grove & $\mathrm{RI}<1.0$ & $1.0<\mathrm{RI}<2.0$ & $2.0<\mathrm{RI}<3.9$ \\
\hline \multirow{2}{*}{2010} & $\mathrm{IR}$ & $32.45 \pm 2.57$ & $45.36 \pm 2.29$ & $38.04 \pm 4.45$ \\
& $\mathrm{RF}$ & $40.29 \pm 3.46$ & $42.18 \pm 5.29$ & $36.60 \pm 2.17$ \\
2011 & $\mathrm{IR}$ & $22.55 \pm 1.05$ & $27.92 \pm 1.96$ & $19.52 \pm 2.41$ \\
& $\mathrm{RF}$ & $22.79 \pm 4.34$ & $22.51 \pm 2.70$ & $35.21 \pm 4.64$ \\
\hline
\end{tabular}

of a complex mixture of more than two hundred volatile compounds, among which saturated and unsaturated aldehydes, alcohols and esters of alcohols of six carbon atoms are especially abundant, accounting for more than $80 \%$ of all of the volatile components in all of the samples analyzed (Peres et al., 2013a). Particularly important was the concentration of the aldehyde trans-2-hexenal, which was also reported in several other studies to account itself for more than $50 \%$ of those volatile fractions in European olive oils (Angerosa and Basti, 2003; Angerosa et al., 1999; Aparicio et al., 2012; Berlioz et al., 2006; Campeol et al., 2003; Cavalli et al., 2004; Tena et al., 2007; Tura et al., 2013; Vichi et al., 2003).

Virgin olive oils produced from healthy fruits, where the LOX pathway is the predominant source of compounds biogeneration, are usually described by perception of fruity sensations, freshly cut grass, green fruits such as apple, banana, or vegetables like artichoke, celery or tomato, accompanied by more or less intense taste notes of bitterness and pungency (Angerosa, 2002; Aparicio and Luna, 2002; Cerretani et al., 2008c). This confirms that most of the volatile compounds responsible for the "green odor" notes of the aroma of fruits and vegetables are produced by the degradation of polyunsaturated fatty acids through the lipoxygenase pathway (Hatanaka, 1996) (Fig. 2).

The profile of volatile compounds present in the aroma of virgin olive oils with sensory defects is quite different (GarcíaGonzález and Aparicio, 2002; García-González et al., 2007; Morales et al., 2005). In those oils the concentrations of C6 and C5 compounds are quite lower than those detected in high quality oils or those compounds are even completely absent (Vichi et al., 2008). Oils from microbiologically contaminated olives showed lower amounts of C5 volatiles and higher levels

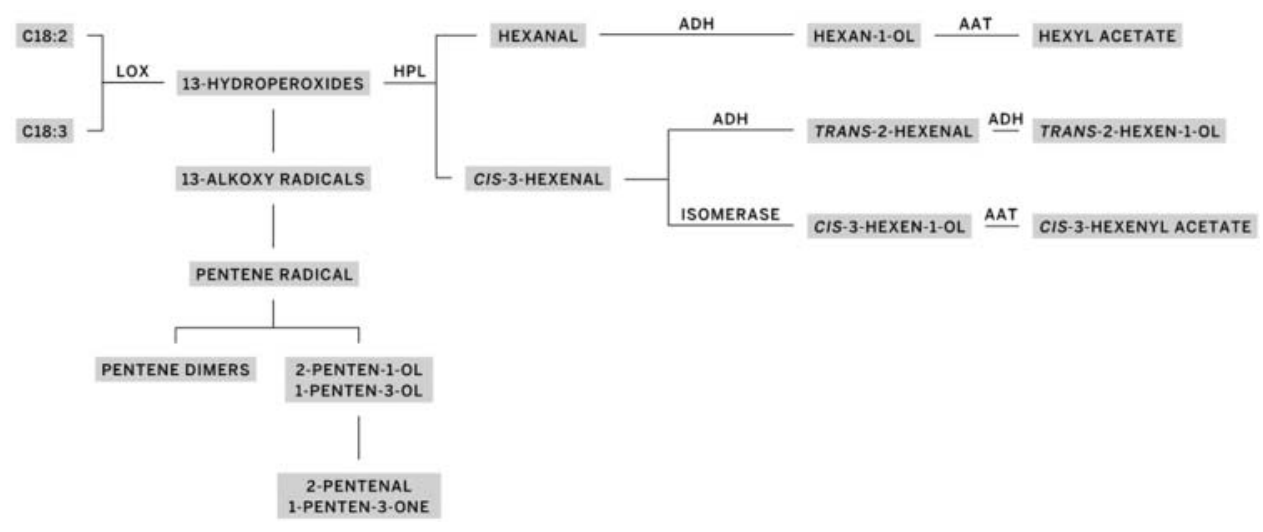

Figure 1. Lipoxygenase pathway involved in the production of C6 and C5 volatile compounds (adapted from Angerosa et al., 2004). 


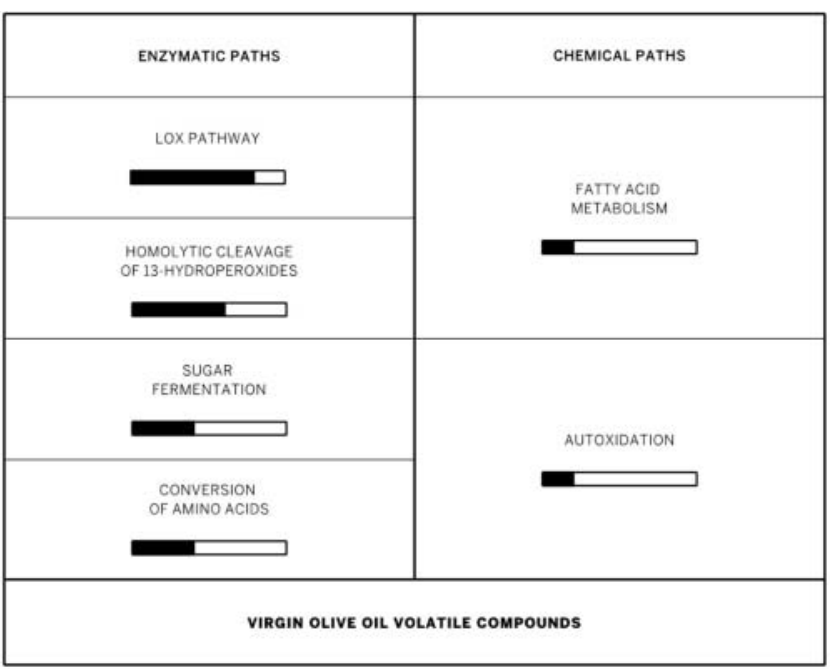

Figure 2. The main pathways involved in the production of volatile compounds of virgin olive oil (adapted from Angerosa, 2002). The size of the black bar gives an idea of the importance of each path.

of C6 volatiles from the lipoxygenase pathway and some fermentation products (Vichi et al., 2011). Penicillium (a storage fungi) was identified as the most potent enzyme producer in olives microbiota, with yields for LOX of $6.8 \mathrm{U} \mathrm{mg}^{-1}$ (Fakas et al., 2010).

At the same time, $\mathrm{C} 7-\mathrm{C} 11$ monounsaturated aldehydes or C6, C9 dienals or C5 branched aldehydes or some C8 ketones become important contributors to the oil aroma. Some of these compounds are responsible for virgin olive oil defects, such as rancid, winey-vinegary, fusty, muddy sediment or musty (Angerosa, 2002; Morales et al., 2005; Morales et al., 1997). Branched chain volatiles, supposed to be formed through aminoacid conversion (Fig. 2) are more likely derived from ketoacids (Kochevenko et al., 2012).

The most determinant steps of the LOX pathway are the peroxidation of linoleic or linolenic acid by the action of lipoxygenase and then hydroperoxide lyase (HPL) catalyzes the cleavage of hydroperoxides from polyunsaturated fatty acids to yield oxoacids and volatile aldehydes (Salas et al., 2005).

The strict specificity of HPL of olive pulp for the n- 6 hydroperoxide derivatives from both linoleic and $\alpha$-linolenic acids, can explain the absence of C9 volatile compounds in the aroma of olive oil (Morales et al., 1995; Salas and Sánchez, 1999).

HPL has been shown to be heat-labile and presented optimal activity under slightly acidic conditions (Anthon and Barrett, 2003; Salas et al., 2000). The existence of only one HPL isoform was suggested using data on thermal stabilities of HPL (Luaces et al., 2007b). Maximum activity has been observed at $15^{\circ} \mathrm{C}$ (Anthon and Barrett, 2003), with a clear decline at $35^{\circ} \mathrm{C}$ (Salas and Sánchez, 1999). Thermal stabilities of LOX and HPL enzymatic activities in crude preparations seem to explain the observed decrease of volatile contents as a consequence of heat treatments of olive fruit.

The changes observed in HPL activity during fruit development (from 13 weeks after flowering to 34 weeks after flowering) showed that HPL activity was higher in green olives harvested at the early developmental stages. Thereafter, it decreased slightly to a high constant level along the entire maturation period. Moreover, results proved that only the availability of the HPL substrate could be the limit to volatile aldehyde formation (Salas and Sánchez, 1999; Sánchez-Ortiz et al., 2013).

Other enzymatic systems within the LOX pathway, such as the $\mathrm{ADH}$ and AAT enzymatic activities remained apparently unaffected as a consequence of hot-water treatment, so that C6 alcohol and ester contents showed almost no variation (Pérez et al., 2003). Alcohol dehydrogenase (ADH) catalyzes the reversible reduction of aliphatic aldehydes to alcohols. Olive stones seem to be a good source of $\mathrm{ADH}$, which is more specific for saturated C6 aldehydes (Luaces et al., 2003). Alcohol acetyl transferase (AAT) catalyzes the formation of acetate esters through acetyl-CoA derivatives. In olive oils, ethyl propionate and hexyl acetate are responsible for the sweet and fruity notes (Salas, 2004; Sánchez and Harwood, 2002).

In conclusion, the biosynthesis of VOO aroma compounds depends mainly on the availability of nonesterified polyunsaturated fatty acids, especially linolenic acid, during the extraction process and on the enzymatic activity of the lipoxygenase/hydroperoxide lyase system. Both availability of substrates and enzymatic activity seem to be cultivar-dependent (Sánchez-Ortiz et al., 2007).

\section{Peroxidases}

Peroxidases (EC 1.11.1.7) are mainly heme-iron enzymes that catalyze the reduction of hydrogen peroxide in the presence of a hydrogen donor.

These class of oxidoreductases are highly specific for hydrogen peroxide, but other organic peroxides, or peroxy acids of the general formula $\mathrm{ROOH}$ can also be used as hydrogen acceptors (Laane et al., 2003; Yuan and Jiang, 2003).

Simultaneously they can be very nonspecific enzymes for the other substrate that act like the hydrogen donor. In fact peroxidases (POD) catalyzes the oxidation of a variety of organic and inorganic hydrogen donors, such as phenols, aromatic amines, aminophenols, diamines, indophenols, ascorbate, even several amino acids, and can also be able to catalyze other type of reactions such as oxidation and hydroxylation (Laane et al., 2003).

POD are widely distributed in different plant parts, with the highest activity in roots; POD contents are dependent on plant species, season and growth conditions. In plant cells, POD are located in soluble form, in the cytoplasm, and also in cell-wall bound form (Vámos -Vigyázó and Haard, 1981; Yuan and Jiang, 2003).

Plant POD play very important roles in physiological processes extensively referred by several authors, such as degrading and synthesizing lignin in cell wall, scavenging of reactive oxidative species in response to oxidative stress (catalyzing the removal of excess hydrogen peroxide), participate in defense mechanism against abiotic and biotic stress (like protection against pathogen attack), tolerance, auxin catabolism and other phyto hormones like indole acetic acid (IAA) (Martins et al., 2013; Mourato et al., 2012; Vergara-Domínguez et al., 2013; Yuan and Jiang, 2003).

After olive puncture by olive fly (Bactrocera olea (Gmelin)) attack, high levels of peroxidase activity were detected, indicating this key role in the defense response against insect injuries (Spadafora et al., 2008) and other biotic stress.

The peroxidases catalyze the oxidation of phenolic compounds using either hydrogen peroxide $\mathrm{H}_{2} \mathrm{O}_{2}$ or organic 
Table 3. Maximum guaiacol POD activity levels found in different olive fruit tissues.

\begin{tabular}{llcc}
\hline Cultivar & Plant tissue & $\begin{array}{c}\text { POD activity } \\
\left(\mathrm{Ug}^{-1} \mathrm{FW}\right)\end{array}$ & Reference \\
\hline Arbequina & seed & $15.20 \pm 1.6$ & $\begin{array}{c}\text { García-Rodríguez } \\
\text { et al. (2011) }\end{array}$ \\
Picual & seed & $20.81 \pm 2.2$ & \\
Arbequina & mesocarp & $0.17 \pm 0.05$ & \\
Picual & mesocarp & $0.05 \pm 0.04$ & \\
Galega Vulgar & seed & $15.7 \pm 1.8$ & Peres et al. (2011) \\
Cobrançosa & seed & $11.8 \pm 0.8$ & \\
Galega Vulgar & mesocarp & $2.0 \pm 0.11$ & \\
Cobrançosa & mesocarp & $2.4 \pm 0.04$ & \\
\hline
\end{tabular}

peroxides as the oxidizing agent, thus producing free radicals, highly reactive and easily polymerizable intermediates. While the phenol oxidation by POD activity is limited to the low internal hydrogen peroxide concentration, the autoxidation of phenol compounds in damaged tissues increase the $\mathrm{H}_{2} \mathrm{O}_{2}$ availability (Takahama and Oniki, 2000). Thus, polyphenol oxidases (PPO) and POD might act synergistically on the oxidative degradation of olive phenolic compounds (Tomás-Barberán and Espín, 2001).

Both PPO and POD activities present in olive fruit at different ripening stages are able to oxidize the main phenol glycosides present in the fruit, as well as those phenol compounds arising from the extraction process, especially secoiridoid compounds derived from oleuropein. Therefore, the activity of endogenous olive PPO and POD enzymes play an important role in the phenolic profile of VOO (García-Rodríguez et al., 2015; Romero-Segura et al., 2012).

Olive seed contains a high level of POD activity (72.4 U $\mathrm{g}^{-1} \mathrm{FW}$ ), accounting for more than $98 \%$ of total POD activity in the whole fruit in three main Spanish cultivars (Luaces et al., 2007a). The presence of peroxidase activity, mainly in the seed, was also reported for other cultivars (García-Rodríguez et al., 2011; Peres et al., 2011; Servili et al., 2003b). Moreover, olive seed POD activity was undetectable before 20 weeks after flowering (WAF) in Picual and Arbequina cultivars and has a maximum level at $28 \mathrm{WAF}$, reaching 20.8 and $15.20 \mathrm{U} \mathrm{g}^{-1} \mathrm{FW}$ in Picual and Arbequina fruits, respectively, remaining at constant levels thereafter (García-Rodríguez et al., 2011). Table 3 shows some results of maximum POD activity in pulp and seed found for some Spanish and Portuguese cultivars.

The storage of Arbequina olives at $4^{\circ} \mathrm{C}$ and at $20^{\circ} \mathrm{C}$ during four weeks in plastic containers showed that POD in olive seeds during storage and ripening have almost the same behavior, showing a gradual increase in activity from 9 to $14-15 \mathrm{U} \mathrm{g}^{-1}$ FW (Hbaieb et al., 2015).

The purification and characterization of POD of Douro cultivar in the black ripening stage showed that the predominant anionic fraction (PODa4) showed an isoelectric point at 4.4 and optimum $\mathrm{pH}$ at 7.0 (optimum temperature of $34.7^{\circ} \mathrm{C}$ ) (Saraiva et al., 2007). However, the $\mathrm{pH}$ optimum of the peroxidasecatalyzed oxidation depended on the substrate used, varying from 4.0 to 6.0 (Tzika et al., 2009).

Concerning the thermal stability, POD loses 60 and $85 \%$ of its activity at $40^{\circ} \mathrm{C}$ for 5 and $10 \mathrm{~min}$, respectively, and no measurable activity could be detected upon heating at 50 and $60^{\circ} \mathrm{C}$ for $5 \mathrm{~min}$ (Clodoveo et al., 2014). However, Taticchi et al.
(2013) found that olive POD showed the highest activity at $37^{\circ} \mathrm{C}$ and high stability in the temperature range tested $(0$ $60^{\circ} \mathrm{C}$ ). Olive POD of cultivar Koroneiki showed a very good stability during $45 \mathrm{~min}$ of incubation at 30 and $60^{\circ} \mathrm{C}$, while at $40^{\circ} \mathrm{C}, 34.5 \%$ inactivation was noticed after $10 \mathrm{~min}$ of incubation (Tzika et al., 2009).

Concerning substrate specificity, POD was unable to oxidize oleuropein, one of the major olive fruit polyphenol, as well as coumaric, ferulic, ascorbic, and p-hydroxybenzoic acids; although other phenolic compounds, such as gallic acid and protocatechuic acid, were found to be olive POD substrates (Tzika et al., 2009). Plant peroxidases preferencially oxidise phenols at the expense of peroxide species, mainly hydrogen peroxide. So, when the content of $\mathrm{H}_{2} \mathrm{O}_{2}$ was rised $(500 \mu \mathrm{L}$ $\mathrm{kg}^{-1}$ ) in the malaxation process, the oxidative degradation of phenols increased as well by $50 \%$ in Picual ripened fruits (mainly hydroxytyrosol derived secoiridoids) (GarcíaRodríguez et al., 2015).

Since the oxidation of endogenous olive oil phenols plays an important role in olive oil stability, the molecular structure of the phenol as well as its topology inside the olive oil microemulsion, may be crucial for its availability for oxidation by olive fruit POD (Tzika et al., 2009).

\section{Polyphenol oxidases}

Polyphenol oxidases (PPO) is a generic name for enzymes that are copper containing metalloproteins, found almost universally in animals, plants, fungi, and bacteria. These enzymes are also known as tyrosinase, phenolase, catechol oxidase, catecholase, o-diphenol oxidase, monophenol oxidase, and cresolase, due to the diversity and complexity of the reactions that can be involved (Whitaker, 1995).

Two main reactions are catalyzed by this class of enzymes in the presence of molecular oxygen (Ramírez et al., 2003; Yoruk and Marshal, 2003) known as:

- hydroxylation of monohydroxyphenols (such as $p$-cresol) to $o$-diphenols catalyzed by monophenol oxidase (EC 1.14.18.1; monophenolase or cresolase activity) (Equation 1).

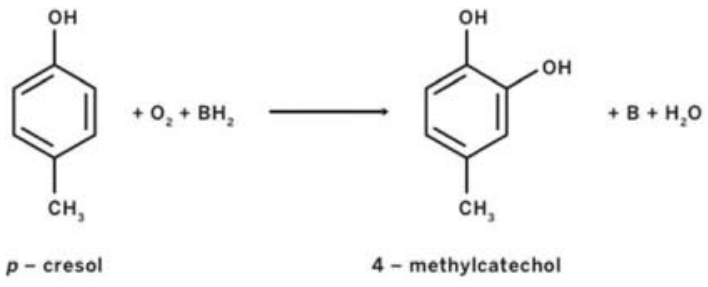

(1)

- oxidation of $o$-dihydroxyphenols such as catechol, to $o$ quinones, by removal of the hydrogens of the hydroxyl groups converting them on benzoquinones catalyzed by $o$-diphenol oxidase PPO (EC 1.10.3.1; diphenolase or catecholase activity) (Equation 2).

2

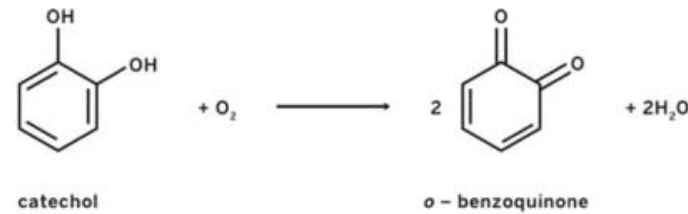

(2) 
The resulting benzoquinones formed by $o$-diphenol oxidase are also precursors of many other compounds, as they are very reactive nonenzymatically in the presence of $\mathrm{O}_{2}$, with sulfhydryl compounds, amines, amino acids, and proteins. Some colored compounds (yellow, red, brown, or black) can be formed by these reactions (Ramírez et al., 2003).

These enzymes are located at the inner face of the thylakoids and in the mitochondria (Vaughn and Duke, 1981; Whitaker, 1995). They act on redox reactions that occur during fruit ripening and in response to injury by biotic factors as well as other abiotic stress conditions. PPO has been associated with several cellular processes including resistance to pathogens and herbivores, as well as resistance to stress conditions, and it may be involved in pathogenesis during attack by fungi or other organisms (Mayer, 1986).

PPOs are capable of oxidizing several phenolic compounds reducing the bitter taste associated to these compounds in different food products. The use of laccase to debittering olives by treating stoned, chopped olives was referred as one of the benefic effects of PPO (Laane et al., 2003). Several authors have studied the time course of fruit PPO activity in several olive cultivars and during fruit ripening (Ebrahimzadeh et al., 2003; Goupy et al., 1991; Ortega-Garcia et al., 2008; Sciancalepore, 1985). The browning rate is well correlated with $o$-diphenol content and polyphenol oxidase activity. The process that leads to browning in the damage areas of olive fruits can be explained by an enzymatic release of hydroxytyrosol from several secoiridoids of the olive fruit due to the action of beta-glycosidase and esterases (Segovia-Bravo et al., 2009). Simultaneously, an additional hydroxytyrosol release, at a less extent than the enzymatic reaction, can also be produced because of the chemical hydrolysis of oleuropein. In a second phase, endogenous fruit PPOs oxidize hydroxytyrosol together with verbascoside. Due to the $\mathrm{pH}$ value of the olive flesh $(\mathrm{pH} \sim 5)$, chemical oxidation of hydroxytyrosol is limited, when compared to the effect caused by the enzymatic action (Brenes-Balbuena et al., 1992).

Results of the kinetics and molecular characterization of $\mathrm{PPO}$ in fruits and leaves during ripening of the olive tree $\mathrm{cv}$. Picual showed an increase in PPO-specific activity during fruit ripening for all substrates tested, such as catechol and catechin (Ortega-Garcia et al., 2008). Moreover, a new $36-\mathrm{kDa}$ PPO protein was detected in fruits during the last stages of fruit ripening, which may indicate that a new PPO isoform could be present during this stage.

PPO activity was found to be largely present in the fruit mesocarp while no PPO activity was detected in seeds (García-Rodríguez et al., 2011; Peres et al., 2011). Moreover, PPO displays relatively constant values after the onset of fruit ripening (García-Rodríguez et al., 2011). Experiments carried out by us with Cobrançosa and Galega Vulgar Portuguese cultivars showed that $\mathrm{PPO}$ activity present in the fruit shows a maximum activity that can be related to ripening index and is dependent on the cultivar (Fig. 3) (Peres et al., 2013b).

A possible relationship between phenylalanine ammonia lyase (PAL), PPO, and total phenols in Picual, Arbequina, Verdial, and Frantoio cultivars throughout ripening was performed. The levels of PAL and PPO seem to be coordinated in the different cultivars during ripening (Ortega-García and Peragón, 2010).



Figure 3. Polyphenol oxidase activity along fruit ripening for two cultivars Cobrançosa (Cob) and Galega (Gal) in 2010 harvest season.

Maximum activity of PPO from the Manzanilla cultivar was found to be at $\mathrm{pH}$ 6.0. In addition, the enzymatic activity increased with temperature $\left(8-25^{\circ} \mathrm{C}\right)$ and was completely inhibited at $\mathrm{pH}$ values below 3.0 regardless of temperature. However, in alkaline conditions, $\mathrm{pH}$ inhibition depended on temperature and was observed at values above 9.0 and 11.0 at 8 and $25^{\circ} \mathrm{C}$, respectively (Segovia-Bravo et al., 2009).

During 7 days of olives storage at $15^{\circ} \mathrm{C}$, the activity of $\mathrm{PPO}$ in the olive pulp decreased drastically in the first 2 days, and then decreased gradually, whereas POD activity showed a gradual reduction throughout the entire storage period. Simultaneously, the PPO activity produced by the spontaneous microbiota in olives, increased along the storage period reaching the maximum levels after the third day of fruit storage (Zullo et al., 2014).

When olives of Arbequina fruits were stored at $4^{\circ} \mathrm{C}$ for one month, PPO activity followed the same trend as that in fresh fruit, and was significantly higher than in fruits stored at $20^{\circ} \mathrm{C}$ (Hbaieb et al., 2015).

Regarding the thermal stability, PPO has a high stability at $20^{\circ} \mathrm{C}$, but a high degree of inactivation at $40^{\circ} \mathrm{C}$, with a large variation in stability according to the olive cultivar (Taticchi et al., 2013).

The oxygen dissolved in the pastes during the malaxation process, activates POD and PPO, which oxidize phenolic compounds and consequently reduce their concentration in VOOs obtained from pastes malaxed at high temperatures. The traditional malaxer, which allows a high amount of oxygen dissolved in the paste during the process due to air contact, represents a classical example of the aforementioned relationship between high temperatures and VOO phenolic loss (Clodoveo et al., 2014).

PPO seems to be the most relevant enzyme involved in phenolic oxidation during crushing. Thus, it is important to find suitable inhibitors of this type of phenolic degradation. Citric acid or the addition of citric fruits seems to be a way to control phenol oxidation, by restraining the activity of these enzymes, producing VOO with higher oxidative stability (Aliakbarian et al., 2009; Cerretani et al., 2008b).

\section{Hydrolases}

These enzymes involve hydrolytic reactions and their reversal (degradation of $\mathrm{H}_{2} \mathrm{O}$ to $\mathrm{OH}^{-}$and $\mathrm{H}^{+}$products). Hydrolases 
Table 4. Acidity, peroxide value (PV), heptanal, octanal and nonanal from Ottobratica olive oil extracted from healthy and damaged fruits by anthracnose (adapted from Runcio et al., 2008).

\begin{tabular}{lccccc}
\hline $\begin{array}{l}\text { Fruits } \\
\text { characteristics }\end{array}$ & $\begin{array}{c}\text { Acidity (\% } \\
\text { oleic acid) }\end{array}$ & $\begin{array}{c}\mathrm{PV}(\mathrm{meq} \\
\left.\mathrm{O}_{2} \mathrm{~kg}^{-1}\right)\end{array}$ & $\begin{array}{c}\text { Heptanal } \\
\left(\mathrm{mg} \mathrm{kg}^{-1}\right)\end{array}$ & $\begin{array}{c}\text { Octanal } \\
\left(\mathrm{mg} \mathrm{kg}^{-1}\right)\end{array}$ & $\begin{array}{c}\text { Nonanal } \\
\left(\mathrm{mg} \mathrm{kg}^{-1}\right)\end{array}$ \\
\hline $\begin{array}{l}\text { Healthy } \\
\text { Half damaged }\end{array}$ & 0.3 & 5 & 1.5 & 0.15 & 1.5 \\
$\begin{array}{l}\text { Completely } \\
\text { damaged }\end{array}$ & 7.7 & 16 & 2.79 & 0.43 & 5.25 \\
\hline
\end{tabular}

use water as a second substrate, and participate in the breakage of the covalent bonds in all biological polymers, such as peptide bonds in proteins, glycosidic bonds in carbohydrates and ester bonds in lipids (Whitaker, 2003).

In the field of olive oil technology the most commonly referred hydrolases are lipases and several other glycosidases.

\section{Lipases}

Lipases (glycerol ester hydrolase or triacylglycerol acylhydrolase; EC 3.1.1.3) catalyze the hydrolysis of ester bonds at the interface between an aqueous and nonaqueous phase and are the first enzymes responsible for the degradation path of stored triacylglycerols (TAGs). Hydrolysis of TAGs by lipases can yield di- and monoacylglycerols, glycerol, and free fatty acids (FFAs). The FFAs released by lipase hydrolytic activity act as a substrate for lipoxygenase activity to produce hydroperoxides.

Olive lipase exhibited a maximum activity at $\mathrm{pH} 5.0$ using triolein as substrate; the presence of calcium increases enzyme activity while the presence of copper reduces this activity by 75\% (Panzanaro et al., 2010). However, other results showed that crude olive extracts had an optimal acylhydrolase activity around pH 8.5 (Olias et al., 1993) and pH 7.0 (Fadiloğlu and Söylemez, 1997).

Studies on lipase activity in olives of cv. Ogliarola, at four stages of ripening defined by olives green to purple skin color, showed that mesocarp lipase activity increases during olive development but declines at purple stage (Panzanaro et al., 2010). The same authors tested the catalytic activity of olive lipase at different temperatures $\left(25\right.$ to $\left.45^{\circ} \mathrm{C}\right)$ and found maximum activity at $35^{\circ} \mathrm{C}$.

Moreover, olive TAG can also be hydrolyzed by an active lipase present in olive seeds, as well as by exogenous lipases produced by certain fungi, such as Colletotrichum spp. (Salas et al., 2000).

Although fruit endogenous lipase may be responsible for some TAG hydrolysis, the fruit microbiota (lactic and enteric bacteria, fungi and Pseudomonas) has the main influence in the extent of the hydrolytic process (Vichi et al., 2011). Penicillium has been identified as the most potent lipase enzyme producer (with yields of $7300 \mathrm{UL}^{-1}$ ), which is mostly active at the beginning of its growth (Fakas et al., 2010).

The presence of lipase-positive yeasts in olive oil, immediately after its extraction having an opalescent appearance due to the presence of solid particles and micro-drops of vegetation water, was also demonstrated (Ciafardini et al., 2006b). Laboratory tests highlighted a substantial increase in total diacylglycerols and free fatty acids in the samples of olive oil inoculated with lipase-producing strains of yeasts, isolated from extra virgin olive oil, W. californica 1639 and S. cerevisiae 1525 (Ciafardini et al., 2006a).

Harvesting time, harvesting methods and the post-harvesting are the main aspects to control the activity of lipase enzymes especially those coming from fruit microbiota. Olive anthracnose caused by Colletotrichum spp. is the disease that can cause the main impact on hydrolytic changes of fruits. The lipases produced by this fungus are the most important factor responsible for high acidity of VOO extracted from completely damaged fruit as well as off-flavors (Table 4) (Runcio et al., 2008).

\section{Glycosidases}

Glycosidases, also called glycoside hydrolases, are enzymes that act in the hydrolysis of the $\beta$-glycosidic bond between two glycone residues or that between glucose and an aryl or alkyl aglycone (Esen, 2003).

Glycosidases are classified under hydrolases, included in subclass EC 3.2. The subclass 3.1 includes esterases (EC 3.1 acting on ester bonds) that can be divided into several sub-subclasses according to specific bond linkage, such as EC 3.1.1 for those acting on carboxylic esters, thioester hydrolases (EC 3.1.2), phosphoric monoester hydrolases, known as phosphatases (EC 3.1.3), phosphodiester hydrolases (EC 3.1.4), triphosphoric monoester hydrolases (EC 3.1.5), sulfatases (EC 3.1.6), diphosphoric monoesterases (EC 3.1.7) and phosphoric triester hydrolases (EC 3.1.8) (IUBMB, 2015).

Plant materials contain different glycoside enzymes considering the existing complex mixture of simple and complex glycosides. Several kinds of glycoside hydrolases are involved in cell wall polysaccharide degradation, as well as other glycoside enzymes, which are able to hydrolyze crosslinkages between different polysaccharides, lignin and proteins.

There are numerous enzymes involved in the degradation of cell wall polysaccharides that includes enzymes acting on cellulose and noncellulosic biopolymers, hemicelluloses (xyloglucans, xylans, arabinoxylan), pectic polysaccharides and proteins. These enzymes can be exo or endo glycoside enzymes, depending on whether they act at the end or in the middle of an oligo/polysaccharide chain, respectively (Esen, 2003).

The degradation of cell wall polysaccharides is performed by exopolysaccharidases, endopolysaccharidases and other hydrolases that do not belong to these two groups, involved in break of noncarbohydrate groups linked to wall polysaccharides such as $O$-acetyl, $O$-methyl and others. Exopolysaccharidases causes hydrolysis progressively from the nonreducing terminus, and endopolysaccharidases attack the polysaccharide backbone at any position (Minic and Jouanin, 2006).

The major polysaccharides in the cell wall and middle lamella contributing to olive fruit texture were found to be the pectic polysaccharides and the hemicellulosic polysaccharides xyloglucan and xylan (Vierhuis et al., 2000). During ripening, multiple enzymes contribute to the degradation of complex organization of the cell wall polysaccharides. These include glycoside hydrolases enzymes such as polygalacturonases (PGs), $\beta$-D-galactosidases, endo- $\beta$-1,4-D-glucanases, and to a lesser extent endo- $\beta$-mannanases, $\beta$-D-xylosidases, $\alpha$-D-galactosidase (Minic, 2008). 
The progressive loss of firmness is the result of a gradual solubilization of protopectin in the cell walls to form pectin and other products. Solubilization followed by depolymerization and deesterification of pectic polysaccharides is the most apparent change occurring during ripening of many fruits like olives (Jimenez et al., 2001). These changes are due to the action of different specific glycosidases that act on cell wall polymers, resulting in their partial or complete degradation. Most of these enzymes are present in low levels and are constitutive throughout fruit development and ripening. However, during ripening, generally all the hydrolases increase in activity, particularly cell wall hydrolases, showing a peak activity at climacteric stage (Prasanna et al., 2007).

The cell wall enzymes, responsible for the changes occurring in the pectic fraction of fruits during ripening and processing, are pectinases, which hydrolyze pectin by different mechanisms.

These enzymes are divided into two broad classes: pectinesterase (PE) and pectin depolymerases (Belitz et al., 2009). PE (EC 3.1.1.11) is a cell-wall-associated enzyme that presents a lot of isoforms facilitating plant cell wall modification and subsequent degradation. In plants, $\mathrm{PE}$ plays an important role in cell wall metabolism during fruit ripening. PE catalyzes the deesterification of the methoxyl group of pectin forming pectic acid. The enzyme acts preferentially on a methyl ester group of galacturonate unit next to a nonesterified galacturonate unit (Kashyap et al., 2001). Pectin depolymerases readily split the main chain and they are further classified as polygalacturonase (PG) and pectinlyases (PLs). The depolymerases catalyze the cleavage of glycosidic bonds via hydrolysis (hydrolases) or via $\beta$-elimination (lyases) (Hadj-Taieb et al., 2002).

The polysaccharides of olive pulp mainly consist of pectic polysaccharides rich in arabinose, glucuronoxylans, cellulose and minor components as xyloglucans, mannans and glycoproteins (Coimbra et al., 1996; Coimbra et al., 1994; Vierhuis et al., 2003). Seven glycosidases, namely $\beta$-glycosidase (EC 3.2.1.21) $\alpha$-galactosidase (EC 3.2.1.22), $\beta$-galactosidase (EC 3.2.1.23), $\alpha$-arabinosidase (EC 3.2.1.55), $\alpha$-mannosidase (EC 3.2.1,24), $\beta$-xylosidase (EC 3.2.1.37), and $\beta$ - $\mathrm{N}$-acetylglucosamidase (EC 3.2.1.30), as well as CX-cellulase (EC 3.2.1.4) and endo-polygalacturonase (EC 3.2.1.15), were identified in olive pulp cell wall preparations, at four ripening stages (Fernández-Bolaños et al., 1995). Many enzymes of this group are involved in a variety of physiological functions such as plant defence, signalling, metabolism of cell wall and lignification (Minic, 2008). Olive fruits can be seriously deteriorated by pre and postharvest damage due to the attack of insects, such as the olive fruit fly, which strongly alters the quality of olives (Rojnić et al., 2015). Olive fruits susceptible to fly infestation could be related to the ability of the oleuropein-degrading-[beta]-glycosidase to produce the highly reactive molecules in the damaged tissues.
The enzyme $\beta$-glycosidase (EC 3.2.1.21) is involved in the degradation of oleuropein (Fig. 4) and has been shown to play a critical role in shaping the phenolic profile of VOO (GarcíaRodríguez et al., 2015). Both esterase and $\beta$-glycosidase are naturally present in olive pulp (Fernández-Bolaños et al., 1995). Both pathways produce hydroxytyrosol, glucose and elenolic acid as final compounds (Fig. 4) (Segovia-Bravo et al., 2009).

Moreover, a clear correlation was established between the contents of oleuropein in olive fruits and the amount in the corresponding VOO of 3,4-DHPEA-EA and respective isomers (oleuropein derivatives). However, no relationship was found between the contents of demethyloleuropein in the fruit and the presence of its derived compound 3,4-DHPEA-EDA in VOO (Romero-Segura et al., 2012). The higher selectivity of olive $\beta$-glycosidase towards oleuropein results in the formation of 3,4-DHPEA-EA. Thus, it is suggested that during VOO extraction, when no demethyloleuropein is available, 3,4 -DHPEA-EDA may be formed by the sequential action of olive $\beta$-glycosidase together with an endogenous methylesterase acting on the initial products of oleuropein hydrolysis (RomeroSegura et al., 2012).

The purified olive $\beta$-glycosidase exhibited a broad optimum $\mathrm{pH}$ curve with a maximum at $\mathrm{pH} 5.5$ and a rapid decline of activity for higher $\mathrm{pH}$ values. This maximum $\mathrm{pH}$ is higher than those previously used to assay olive glycosidases (Heredia et al., 1993). Furthermore, the highest activity was observed at $45^{\circ} \mathrm{C}$, as most plant glycosidases. Thermostability is maintained up to $40^{\circ} \mathrm{C}$ with a dramatic decrease of activity above this temperature (Romero-Segura et al., 2009).

During fruit ripening, $\beta$-glycosidases are implicated in fruit debittering by oleuropein degradation, and glucose and aglycone molecules release (Brenes-Balbuena et al., 1992; Obied et al., 2008; Ryan et al., 1999). $\beta$-glycosidase location during the ripening of olive fruit, by in situ activity assay, was detected in mesocarp cell chloroplasts and oleuropein (substrate) is restricted in the vacuoles of olive mesocarp cells (Mazzuca et al., 2006). The variations of oleuropein-degradative-[beta]glycosidases activity during ripening are due to changes in the competence of single mesocarp cells to synthesize two different enzyme isoforms (Mazzuca et al., 2006). At 35 weeks after flowering Picual fruits display twice as much $\beta$-glycosidase activity than Arbequina fruits, which seems to explain the higher phenol content found in Picual VOO (Romero-Segura et al., 2012).

Monitoring the activity of olive endogenous $\beta$-glycosidase during fruit ripening and storage, a similar pattern between one month stored fruits at $4^{\circ} \mathrm{C}$ and fresh harvested ones was observed; moreover, the decrease in this enzyme activity is accompanied by a dramatic decrease in the phenolic content of VOO (Hbaieb et al., 2015).

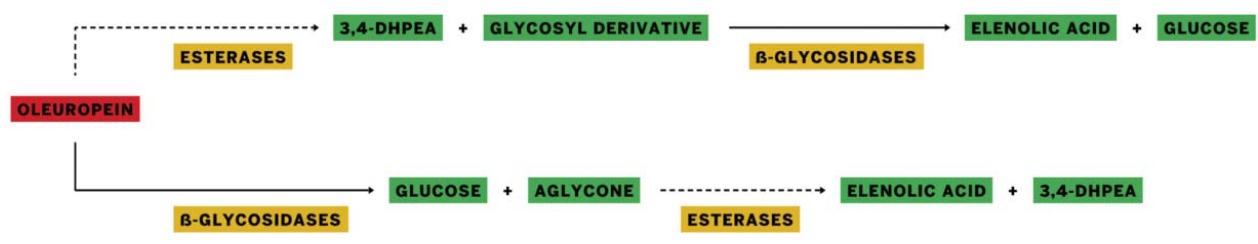

Figure 4. Enzymatic degradation of oleuropein and products formed according to the reaction type (adapted from Segovia-Bravo et al., 2009). 
In conclusion, endogenous enzymes such as $\beta$-glycosidase (which hydrolyzes phenolic glycosides) and oxidoreductases, like PPO and POD (which oxidase phenolic compounds), may be the main biochemical factors affecting the phenolic content of VOO.

\section{Technological factors influencing the activity of the enzymes responsible for some chemical and sensory characteristics of VOO}

Sensory characteristics of VOO are strictly related to the contents of volatile and phenolic compounds, which are strongly affected by the operative conditions of oil extraction process. The occurrence of several enzymatic processes (endogenous and exogenous) may affect the amount and the type of phenolic and volatile compounds in the final VOO.

\section{Olive composition: Cultivars, ripeness, and agro-climatic factors}

The composition of VOO depends primarily on olive fruit composition, which depends on the cultivar, the ripening stage and the environmental growth conditions, such as biotic and abiotic stresses. Several studies have already been carried out with the aim of describing the differences found between the phenol profile of different olive cultivars (Cerretani et al., 2006; Esti et al., 1998; Vinha et al., 2005) as well as their evolution throughout the ripening process (Amiot, 2014; Criado et al., 2004; Morelló et al., 2006; Servili et al., 2009). Moreover, phenolic and volatile compounds in $\mathrm{VOO}$ have been used to discriminate between fruit ripening stages, geographical origin and cultivar (Aparicio and Morales, 1998; Berlioz et al., 2006; Luna et al., 2006; Tura et al., 2013; Vichi et al., 2008); the influence of environment and season on flavor characteristics was also studied (Tura et al., 2009) as well as the site of cultivation on lipophilic and hydrophilic phenols (Tura et al., 2008).

The influence of irrigation on VOO volatile and phenol compounds is an important actual research topic especially for the super high-density orchards (Berenguer et al., 2006; El Riachy et al., 2013; Gómez-Rico et al., 2007).

\section{Harvest and postharvest}

The decision of the harvesting date seems to be a key factor to olive oil quality and one of the aspects that most influence the composition of olive oils. From the point of view of the producer, the following aspects must be considered: (i) the olives must have the maximum weight of oil, (ii) the quality of the oil must be optimal, (iii) fruit and tree damage must be minimal, (iv) next year's crop must not be affected and (v) harvesting must be as cheap as possible (Prenzler et al., 2007). So, the decision of the harvesting date is usually based on local information, productivity and oil amount or fruit quality. These aspects are certainly crucial for the future development of olive industry but other factors may be analyzed as well. Tolerance or sensitiveness to different pests and diseases or meteorological phenomena (frost), studied together with ripening periods, are important points to be evaluated in olive growing.

\section{Storage of the fruits, leaf removal and washing}

The effect of olive storage prior to milling is a very important and studied aspect of olive oil technology (Fernández-Bolaños et al., 1997; Kalua et al., 2008; Pereira et al., 2002; PerezCamino et al., 2001). The drastic reduction of total phenols in the oily fraction of the fruit, observed after three days of storage, can probably be attributed to the activity of the oxidoreductases enzymes either from the pulp or from the microbiota grown in the carposphere or in the pulp of the fruits damaged during the harvesting and storage operations (Zullo et al., 2014). Apart from the condition of the fruit at harvest, as the presence of pests and diseases, differences in post-harvest handling of the fruit, produce olive oils with different flavors and off-flavors (Angerosa et al., 2004; Morales et al., 2005; Vichi et al., 2009b). The storage of the fruits after harvest changes the volatile composition of olive oil. 1-octen-3-ol is related with the sensory defect of mustiness-humidity; ethyl butanoate, propanoic and butanoic acids are responsible for fusty sensory defect; acetic acid, 3-methyl butanol and ethyl acetate for wineyvinegary, while several saturated and unsaturated aldehydes and acids are connected with rancid sensory defect (Morales et al., 2005). The presence of several volatile phenols was also addressed to bad storage conditions of olives (Vichi et al., 2009a; Vichi et al., 2008). So, the storage of fruits before processing is always a nonrecommended practice.

Removing leaves and other foreign materials is the first step in olive oil extraction in order to prevent damages in extraction equipment caused by stones, as well as to avoid the presence of off-flavors. However, the presence of small amounts of leaves may have benefits in terms of $\mathrm{VOO}$ antioxidant characteristics (Malheiro et al., 2013; Sonda et al., 2013).

The washing operation of olives removes soil and pesticides residues but can introduce excessive moisture to the resulting olive paste, leading to a reduction in extractability, because of the formation of water/oil emulsions and to a decrease in hydrophilic phenols due to the extraction of these compounds by the water phase (Uceda et al., 2006). Good practices recommend the frequent renovation of washing water in order to avoid the high microbial concentration in the recycled water and their fermentation activity that might influence sensory VOO quality.

\section{Milling}

Milling is the first unit operation performed in order to prepare the olive paste for olive oil extraction. The crushers, destoner included, as well as time, temperature and oxygen concentration during the malaxation step have shown to influence oxidoreductases activity with consequences on VOO phenolic and volatile composition (Amirante et al., 2007; Servili et al., 2002a; Servili et al., 2007). As a matter of fact, the activity of oxidoreductases, mainly POD, can be quite different comparing destoned and the whole fruits (Table 5).

The main hydrophilic phenols of VOO, such as secoiridoid aglycons, are formed during crushing by the hydrolysis of oleuropein, demethyloleuropein and ligstroside, catalyzed by endogenous $\beta$-glycosidases (Obied et al., 2008). The aglycones are more soluble in the oil phase than the glycoside forms that 
Table 5. Oxidoreductases activity (POD and PPO) in two Italian cultivars in milling and malaxation, using destoned and whole fruit (adapted from Servili et al., 2007).

\begin{tabular}{lccc}
\hline & Cultivar & $\begin{array}{c}\text { POD activity } \\
\left(\mathrm{U} \mathrm{mg}^{-1} \mathrm{DW}\right)\end{array}$ & $\begin{array}{c}\text { PPO activity } \\
\left(\mathrm{U} \mathrm{mg}^{-1} \mathrm{DW}\right)\end{array}$ \\
\hline $\begin{array}{l}\text { Crushed whole olives } \\
\text { Crushed destoned olives }\end{array}$ & 'Frantoio' & $38 \pm 2.0$ & $17 \pm 0.3$ \\
Malaxed whole olives & & $12 \pm 1.4$ & $17 \pm 1.5$ \\
Malaxed destoned olives & & $14 \pm 0.3$ & $10 \pm 0.7$ \\
Crushed olives & $6 \pm 0.3$ & $11 \pm 1.4$ \\
Destoned olives & 'Coratina' & $16 \pm 0.8$ & $5 \pm 0.4$ \\
Malaxed whole olives & & $5 \pm 0.5$ & $6 \pm 0.3$ \\
Malaxed destoned olives & & $7 \pm 0.2$ & $4 \pm 0.4$ \\
& & $3 \pm 0.1$ & $5 \pm 0.4$ \\
\hline
\end{tabular}

remain in the water phase. This observation suggests that it is important to know the adequate conditions to promote $\beta$-glycosidase activity, in order to increase phenol contents of VOO. In addition, if the crushing system inhibits $\beta$-glycosidases activity, a large proportion of water-soluble phenols will be lost in the waste water (Clodoveo et al., 2014).

The impact of crushing in VOO phenolic and volatile compounds can be related to the distribution of the endogenous oxidoreductases and phenolic compounds in the different parts of the olive fruit. As previously reported, POD in combination with $\mathrm{PPO}$, are the main endogenous oxidoreductases responsible for phenol oxidation during processing (García-Rodríguez et al., 2015; García-Rodríguez et al., 2011). POD occurs in high amounts in the olive seed; on the contrary, hydrophilic phenol compounds, are largely concentrated in the pulp, whereas the stone and seed contain only small quantities of these substances (Servili et al., 2004; Servili et al., 2007).

In traditional olive mills, the stone crushers, with two or four granite wheels rotating at $12-15 \mathrm{rpm}$ are used. The energy released during breaking is low and the fact that the paste is not heated prevents the LOX from denaturation (Padilla et al., 2009). However, due to the time of exposure to oxygen several compounds produced from the LOX pathway are lost. This type of crusher reduces the phenolic concentration in olive pastes with milling time, due to air contact during processing. Contact with the air stimulates PPO and POD, producing a high oxidation of phenolic compounds. Other drawbacks of the stone crusher are its low working capacity, the high hourly machine footprint, and its low ability to release the chlorophyll found in the olive skin, responsible for the green color of VOO, into the oil. This aspect is particularly relevant when the stone crusher is combined with a solid-liquid centrifugal separation (Servili et al., 2012). The exposition of the olive paste to the atmospheric oxygen promoting the oxidation of phenol compounds, causes a reduction of oxidative stability as well as a decrease in bitter and pungent intensity of VOO (Di Giovacchino et al., 2002). Therefore, the use of stone mill to process bitter cultivars, like the Italian Coratina is recommended (Clodoveo et al., 2013).

In VOO extraction by centrifugation the crushing operation is usually performed with hammer crushers. Compared to stone crushers, these machines have some benefits that are attributable to their high working capacity, low footprint and low installation costs. This mill extracts the pigments from the olive skin in a very efficient way, giving VOO with higher concentration in beta-carotene, chlorophyll $a$ and pheophytin $a$ to produce greener oils (Domingues et al., 2009; Servili et al., 2002a). However, the hammer crushers show some disadvantages, such as the strong emulsifying effect produced on olive paste during crushing, a considerable increase in paste temperature and the high degradation of the seed tissues which, as mentioned earlier, promotes phenolic oxidation by improving peroxidase activity (Servili et al., 2000). Olives treated by the two crushing systems-hammer and stone mills-were observed by scanning electronic microscopy. Micrographs of olive fruits milled in hammer crushing evidence better cell cuts, in contrast to stone mill where olive cell layers have been broken and damaged. The olive oil extracted from pastes obtained by the hammer crusher shows the highest concentration of phenolic compounds and consequently the strongest antioxidant activity (Veillet et al., 2009). Temperature of the olive paste increases by $13-15^{\circ} \mathrm{C}$ with respect to ambient temperature when a fixed-hammer metallic crusher is used (Di Giovacchino et al., 2002). The diameter of grid in hammer crushers as well as the relative speed of fixed hammers may also have a great impact in yield, phenols and pigments extraction (Di Giovacchino et al., 2002). The more violent grinding causes an increase in temperature and the reduction of HPL activity (Amirante et al., 2006).

Disk crushers crush the olives between two-toothed disks, one stationary and one that rotates. The use of the disk-crusher avoids paste overheating, minimizing the risk of oxidation (Amirante et al., 2010). However, this crusher may promote the formation of emulsions, which inhibit oil-water separation. The use of the disk crusher may also affect the sensory characteristics of the olive oil, which can have a stronger, spicy taste, but less bitter than the one obtained by the hammer-crusher. According to the olive mills manufacturers (e.g. Alfa Laval), this is a technique to obtain "mild taste" or "sweet" olive oils.

A new approach to olive milling is based on separated crushing of the constituent parts of the fruit, such as the skin, pulp, and seed. The destoner, also called "de-pitting" machine, crushes only the pulp tissues (Amirante et al., 2006; Mulinacci et al., 2005). In this type of milling, the degradation process of the olive tissues should be strong for the skin and pulp, in order to facilitate the release of oil and pigments, whereas impact on the seed should be limited. The destoning process, excluding the olive seed with high POD activity, reduces the enzymatic degradation of phenols, largely concentrated in the pulp, improving their concentration in $\mathrm{VOO}$ and consequently their oxidative stability (Amirante et al., 2007; Amirante et al., 2006; Cerretani et al., 2008a; Lavelli and Bondesan, 2005; Mulinacci et al., 2005; Servili et al., 2007). Simultaneously with the

Table 6. Effect of different crushing methods on total phenols and in the volatile aldehydes hexanal and trans-2-hexenal of VOO $\left(\mathrm{mg} \mathrm{kg}^{-1}\right)$.

\begin{tabular}{lcccc}
\hline Types of crushers & Total Phenols & Hexanal & Trans-2-hexenal & References \\
\hline Stone mill & 133 & 28.0 & 321.0 & $\begin{array}{r}\text { Di Giovacchino } \\
\text { et al. (2002) }\end{array}$ \\
Disc metallic & 247 & 27.8 & 121.0 & Servili et al. \\
Hammer mill & 260 & 0.28 & 43.6 & $\begin{array}{c}\text { (2012) } \\
\text { De-stoner }\end{array}$ \\
Stone mill & 320 & 0.58 & 52.2 & $\begin{array}{c}\text { Amirante et al. } \\
(2006)\end{array}$ \\
De-stoner & 237 & 8.1 & 110.8 & 185.4 \\
\hline
\end{tabular}


reduction in phenolic degradation an improvement in the concentration of volatile compounds, especially of hexanal, trans2-hexenal and C6 esters, with a consequent positive increase of the intensity of "cut grass" and "floral" sensory notes occurs (Table 6) (Servili et al., 2007).

Considering that the seeds represent about $25 \%$ of the total paste volume, the use of the destoner can improve the working capacity of the mill plant, excluding about a quarter of the residual solid waste before the extraction process. However, in order to ensure good VOO extraction yields, the destoned olive paste requires long mixing times as well as a third-generation decanter to separate the oil from the olive paste, since the absence of stone fragments causes a change in olive paste rheology (Clodoveo and Hbaieb, 2013).

\section{Malaxation}

From the point of view of yield and VOO quality, malaxation is one of the most important unit operations. The malaxer machine consists of a stainless steel tank containing the olive paste and a malaxing central-screw stirring the paste slowly and continuously, at monitored temperature (Clodoveo, 2012). The oil in olives (about 20-25\%) is found in the mesocarp cells, mainly in the vacuoles and scattered to a lesser extent through the cytoplasm in the form of small lipid inclusions. Mixing and heating $\left(25-35^{\circ} \mathrm{C}\right)$ of the olive pastes during malaxation causes the breakdown of water-oil emulsion, allowing oil droplets to form larger droplets, which separate easily from the aqueous phase during the solid-liquid and liquid-liquid separation processes. Moreover, this operation contributes to activate several natural enzymatic processes after the disruption of olives by milling. However, the knowledge of the critical parameters that control the diffusion and equilibrium phenomena between the aqueous and the oil phases, is crucial, as well as the time needed to trigger enzymatic reactions responsible for the formation of some volatile compounds and for the modification of phenolic compounds (Clodoveo et al., 2014). Many factors, like olive ripeness, olive granulometry in crushing, presence of stone fragments and amount of water may influence these phenomena. Time-temperature relationship is the main critical factor (Peri, 2014).

Operation time, speed of kneading, temperature and atmosphere composition inside the malaxer are the parameters that should be controlled in the malaxation process (Angerosa et al., 2001; Clodoveo, 2012; Inarejos-García et al., 2009; Kalua et al., 2006; Parenti et al., 2008; Pastore et al., 2014; ReboredoRodríguez et al., 2014; Servili et al., 2008). The preservation of phenols and volatile compounds in VOO depends on these parameters. Phenol compounds, once released or formed during olive oil extraction, are distributed between the water (approximately 53\% of the available group of antioxidants in the olive fruit) and oil (1-2\%) phases. Approximately $45 \%$ of the phenols are trapped in the solid phase (pomace) (Clodoveo, 2012). This distribution depends on the solubility of phenol compounds between water and oil. Consequently, only a fraction of the phenol compounds is in the oil phase. In turn, volatile compounds are formed by the action of enzymes from the LOX pathway that begin to act as soon as the fruit is crushed, and continue to act during malaxation. Moreover, due to incorrect "hygienic design" of malaxers, off-odors or off-flavors can arrive in VOO (Peri, 2014).

\section{Temperature}

During the olive paste malaxing process, increasing temperature levels up to $35^{\circ} \mathrm{C}$, favors the activity of oxidoreductase enzymes present in olive fruit, such as PPO and POD (Taticchi et al., 2013). Also, LOX, that catalyzes the formation of hydroperoxides, may be responsible for an indirect oxidation of secoiridoids. Most of these enzymatic reactions occur in the presence of oxygen.

The problems concerning temperature management during malaxation have been extensively studied and a negative relationship between processing temperature and the quality of $\mathrm{VOO}$, namely in the amounts of phenols and volatile compounds with their sensory impact in VOO, has been shown (Di Giovacchino et al., 2002; Garcia et al., 2001; Inarejos-García et al., 2009; Kalua et al., 2006; Servili et al., 2003b). The derivatives of oleuropein, demethyloleuropein and ligstroside are highly affected by the processing temperature, whereas lignans are less affected (Servili et al., 2004).

A significant increase in the secoiridoids of hydroxytyrosol and tyrosol, as the malaxation temperature rises from 20 to $40^{\circ} \mathrm{C}$, is often observed (Di Giovacchino et al., 2002; InarejosGarcía et al., 2009; Ranalli et al., 2001a). This is due to the increase in the partition coefficients of these compounds between the oily and water phases in the olive paste and to the increase of the relative solubility in the oily phase (Rodis et al., 2002).

The optimum temperature found to obtain VOO with high total phenol content was $27^{\circ} \mathrm{C}$ (Parenti et al., 2008). In turn, higher total phenol content was found at $40^{\circ} \mathrm{C}$, for $60 \mathrm{~min}$ in the experimental oil mill pilot plant and during $45 \mathrm{~min}$ for the Abencor laboratory scale system (Inarejos-García et al., 2009). However, VOO obtained in continuous industrial plants at processing temperatures lower than $27^{\circ} \mathrm{C}$, does not show better chemical and sensory properties than the VOO obtained at $35^{\circ} \mathrm{C}$ in the same plants (Boselli et al., 2009).

PPO is characterized by a lower thermal stability than POD. While olive POD showed the highest activity at $37^{\circ} \mathrm{C}$, PPO exhibited the optimum activity at approximately $50^{\circ} \mathrm{C}$, but showed low stability at $40^{\circ} \mathrm{C}$, with a large variation in stability according to the olive cultivar (Taticchi et al., 2013). This can partly explain the variation in phenol concentrations in the paste during processing depending on the temperature used. In general, an increase in temperature (from 25 to $35^{\circ} \mathrm{C}$ ) can reduce the enzymatic oxidative reaction (PPO) causing an increase in both total phenols and in oleocanthal (Taticchi et al., 2014).

At the end of malaxation, the residual activity of PPO in the pastes of Moraiolo cultivar was reduced to 30 and $15 \%$ of the initial PPO activity in crushed pastes at 20 and $35^{\circ} \mathrm{C}$, respectively. The lower values for residual activity of $\mathrm{PPO}$ at $35^{\circ} \mathrm{C}$ appear to confirm the relationship between the phenolic concentration in the oil and the partial inactivation of $\mathrm{PPO}$ at $35^{\circ} \mathrm{C}$ (Taticchi et al., 2013).

The enzymes involved in the LOX pathway such as lipoxygenase, hydroperoxide lyase, alcohol dehydrogenase and alcohol acyltransferase show optimal temperatures between 15 and 
$25^{\circ} \mathrm{C}$, whereas their activity decreases above $30^{\circ} \mathrm{C}$. Hence, when the malaxing process is carried out at temperatures above $35^{\circ} \mathrm{C}$, a reduction in the generation of volatile compounds during malaxation is observed and less "green" and fruity" VOO are obtained (Taticchi et al., 2014). Oils obtained at $45^{\circ} \mathrm{C}$ were rejected because of "heated or burnt" off-flavor (Boselli et al., 2009). Considering the volatile compounds, the main effect of an increase in the malaxing temperature is a loss of esters and cis-3-hexen-1-ol and an accumulation of hexan-1-ol and trans2-hexen-1-ol, responsible for unpleasant odors (Angerosa et al., 2001; Kalua et al., 2006). The activation of amino acid conversion pathway by high temperatures can produce considerable amounts of 2- and 3-methylbutanal, without accumulating any corresponding alcohols, associated with the "fusty" defect (Angerosa et al., 2001).

High malaxation temperature favor the formation of octane, a volatile compound that is produced from the decomposition of 10-hydroxyperoxide of oleic acid and is correlated with "fusty" defect in olive oil (Kalua et al., 2006).

Hexanal formation is promoted at higher temperatures by autoxidation process (Kalua et al., 2006). Based on this, these authors proposed temperatures higher than $35^{\circ} \mathrm{C}$ in malaxation, in order to maximize hexanal formation. However, hexanal odor description, in lower amounts, is green, while in higher amounts (above $900 \mu \mathrm{g} \mathrm{kg}^{-1}$ ), is described as unpleasantly sebaceous (Dierkes et al., 2011).

These results are generally obtained by performing malaxation with the pastes in continuous contact with air, as in the case of open-top malaxation machines. The conclusions can be very different in the new generation malaxation equipments that operate in sealed conditions (Servili et al., 2012).

Therefore, the choice of the mixing temperature is a compromise in order to get high quality $\mathrm{VOO}$, rich in volatiles and phenolic compounds. Lower temperatures than $28-30^{\circ} \mathrm{C}$ are commonly recommended (Angerosa et al., 2001; Angerosa et al., 2004). However, even the use of temperatures of paste below $22^{\circ} \mathrm{C}$, in the new generation of confined malaxer, lead to a decrease in the solubilisation of phenolic compounds and chlorophyll (Taticchi et al., 2014).

\section{Time}

The time of malaxation can also influence VOO composition (Angerosa et al., 2001; Di Giovacchino et al., 2002; InarejosGarcía et al., 2009; Kalua et al., 2006). Therefore, the simultaneous changes in time-temperature during malaxation is a feasible systematic approach to promote changes in phenol and volatile composition (Kalua et al., 2006). Table 7 shows the variables (phenol and volatile compounds) in VOO from Frantoio cultivar affected by malaxation time and temperature according to Kalua et al. (2006) and respective impact on flavor.

Regarding the hydrophilic phenols, these compounds are much more affected by the malaxation temperature than the malaxation time (Angerosa et al., 2001; Fregapane and Salvador, 2013; Inarejos-García et al., 2009).

A longer kneading time apparently affects the phenol contents negatively, favoring either their chemical or enzymatic oxidative degradation, and increasing the presence of some undesirable VOO volatiles (Angerosa et al., 2001; Di
Table 7. Discriminant variables for malaxation time (30,60, 90 and $120 \mathrm{~min})$ and temperature $\left(15,30,45\right.$ and $\left.60^{\circ} \mathrm{C}\right)$, Frantoio cultivar, Abencor extraction system (Kalua et al., 2006).

\begin{tabular}{|c|c|c|}
\hline Parameter & Discriminant variables & Impact on flavor \\
\hline Time & $\begin{array}{l}\text { cis-2-penten-1-ol } \\
\text { hexanal } \\
\text { 3,4-DHPEA-EDA } \\
\text { Acetoxypinoresinol }\end{array}$ & $\begin{array}{l}\text { Olive fruitiness }(0)^{\mathrm{a}} \\
\text { Green apple }(\mathrm{O})^{\mathrm{b}} \\
\text { Bitterness, pungency }(\mathrm{G})^{\mathrm{a}}\end{array}$ \\
\hline Temperature & $\begin{array}{l}\text { 1-penten-3-ol } \\
\text { Hexanal } \\
\text { trans-2-hexenal } \\
\text { Octane } \\
\text { Tyrosol } \\
\text { Vanillic acid } \\
\text { 3,4 -DHPEA-EDA }\end{array}$ & $\begin{array}{l}\text { Grassy }(R)^{\mathrm{a}} \\
\text { Green apple }(0) \\
\text { Green }(0)^{\mathrm{b}} \\
\text { Sweety, alcane }(0)^{\mathrm{b}} \\
\text { Bitterness }(\mathrm{G})^{\mathrm{a}} \\
\text { Bitterness, pungency }(\mathrm{G})^{\mathrm{a}}\end{array}$ \\
\hline
\end{tabular}

O-orthonasal, R-retronasal, G -gustative; ${ }^{a}$ (Cerretani et al., 2008) ${ }^{\text {b}}$ (Morales et al., 2005).

Giovacchino et al., 2002; Inarejos-García et al., 2009; Ranalli et al., 2003c; Stefanoudaki et al., 2011).

However, a reduction in the oxygen availability may decrease the activity of PPO and POD, thus avoiding or even increasing the total phenol content of the oil (Servili et al., 2003a; Servili et al., 2008). A small decrease in the secoiridoid derivatives of hydroxytyrosol, as the malaxation time increased, is observed (about $5-10 \%$ from 30 to $60 \mathrm{~min}$ ), whereas the content of secoiridoids of tyrosol increased (15-30\%) (Angerosa et al., 2001; Di Giovacchino et al., 2002; Inarejos-García et al., 2009).

For the secoiridoid compound 3,4-DHPEA-EDA high concentrations correspond to short malaxation times (Kalua et al., 2006). The main effect of the duration of malaxation is an increment of C6 and C5 carbonyl compounds, especially of hexanal, which represents an important contribution to the olive oil flavor (Amirante et al., 2006). This increase in C6 and C5 volatile compounds was observed, regardless of the temperature adopted. Thus the production of hexanal, seems mainly to be promoted by extending the malaxation operation to more than 45 min (Angerosa et al., 2001; Morales and Aparicio, 1999).

It is now generally recognized that temperature and time of malaxation should be evaluated for each cultivar and rheological condition of the pastes. Consequently, the conditions that maximize quality, without compromising yield, should be tested and optimized by the producer. In industrial practice, the residence times of the pastes at the indicated temperature should not be neglected (Peri, 2014).

\section{Oxygen}

The time of exposure of olive pastes to air contact (TEOPAC) during malaxation was studied as a processing parameter that could be used to control the activity of endogenous oxidoreductases, such as PPO, POD and LOX, which affect virgin olive oil quality. Servili et al. (2003a) analyzed phenol and volatile compounds in VOO using progressive TEOPAC at three ripening stages of olives. The phenol concentration in virgin olive oil progressively decreased with increasing TEOPAC. On the contrary, a positive relationship was found with the concentration of several volatile compounds responsible for virgin olive oil aroma. However, the effect of TEOPAC was strictly related to fruit ripening. 
By monitoring the main process parameters (oxygen availability in the malaxer head-space, temperature, and time), a selective control of enzyme activities as PPO and POD can be performed. So, the introduction of the new generation of malaxation equipments, such as covered malaxer, permits the regulation of $\mathrm{O}_{2}$ concentration in the malaxer headspace. Under these conditions, it is possible to increase hydrophilic phenol contents in the olive pastes and in the corresponding VOO, because of the decrease of phenol oxidation catalyzed by endogenous oxidoreductases. Moreover, in covered malaxer, oxygen concentration can be regulated either by the $\mathrm{CO}_{2}$ naturally produced by the olive pastes during malaxation or using inert gases (Parenti et al., 2006). In fact, saturating the headspace of the malaxer with $\mathrm{CO}_{2}$ allows the reduction of oxidative phenomena avoiding the use of expensive inert gases (Servili, 2014).

Preliminary studies on some Italian cultivars have been performed to define the best malaxation conditions, in terms of temperature and $\mathrm{O}_{2}$ concentration. The recommendations are: malaxation should be carried out without oxygen for the cvs with low phenol content, whereas malaxation should be carried out with controlled supplementation of oxygen for those cultivars characterized with higher phenol contents (Servili et al., 2008). Thus, the optimization of temperature and oxygen concentration requires specific research for each individual cultivar (Selvaggini et al., 2014).

Fruits from Coratina cultivar are characterized by high amount of phenols and low PPO and POD activities (Servili et al., 2007). The low activity of these enzymes can explain that an increase of $\mathrm{O}_{2}$ in the pastes produces a reduction of phenol content in the oils, lower than that connected with the malaxation temperature. As a consequence, in Coratina cv. low processing temperatures seem to be more important than high oxygen concentrations in the reduction of the hydrophilic phenolic compounds in the oils. This phenomenon could be explained by reduced activity of the depolymerizing enzymes in the pastes that decrease the release of phenols from the cell wall into the olive oil (Selvaggini et al., 2014).

When pastes were malaxed under a nitrogen atmosphere, oxidation reactions are repressed and no statistical differences were observed in the phenolic concentration of oils obtained from only crushed or malaxed pastes (García et al., 2001a). However, the industrial use of nitrogen during olive oil processing may have some drawbacks. First, nitrogen should be employed not only during the malaxation step but also during crushing. If oxygen is not removed from the paste during crushing, $o$-diphenols may be oxidized, even if the paste is malaxed under nitrogen. Second, the malaxer machine should be sealed; otherwise a continuous flow of nitrogen in the malaxer should be maintained. Third, from a sensory point of view, an increase of total phenols in oils must also enhance the bitter taste of some olive oils (García et al., 2001a). Therefore, extended induction oxidation time due to increased antioxidant activity was observed in these oils (Yorulmaz et al., 2011).

The reduction of $\mathrm{O}_{2}$ concentration in the malaxing chamber, to values lower than the $\mathrm{O}_{2}$ concentration in air, significantly reduced the formation of lipoxygenase derived volatiles decreasing odors and flavors of artichoke, fresh fruity, and fresh cut grass in VOO (Pastore et al., 2014).

\section{Adjuvants}

In olive oil extraction process, $10-20 \%$ of the oil remains inside the unsheltered cells or is left in the colloidal system of the olive paste - microgels - and some is bound in an emulsion with the vegetable water (Espínola et al., 2009). The difficulty to extract this "bound" oil lies mainly in the fact that the droplets of dispersed or emulsified oil are surrounded by a lipoprotein membrane (phospholipids and proteins) that keeps them in that state. The smaller the size of the droplets, the greater their stability. When this phenomenon is more pronounced, the obtained pastes are called "difficult pastes" and the positive effects of using processing aids are particularly important for these pastes (Petrakis, 2006).

During the last decades, several studies have been performed in order to improve the yield and the quality of olive oil by using processing aids, such as natural microtalc, sodium chloride, enzymes or calcium carbonate adjuvants (Alba et al., 1990; Alba-Mendoza et al., 2005; Espínola et al., 2009, 2011; Moya et al., 2010; Pérez et al., 2008). For inorganic adjuvants the results obtained can be quite different, and very dependent on cultivar, ripening index (Table 8) and extraction conditions (water addition in malaxation, temperature, time).

According to the EU 2568/1991 and 1989/2003 standards, adjuvants can be added, during malaxation to breakdown emulsions in order to promote a high oil extraction yield. The most frequently employed adjuvants are microtalc and in some countries, although not in Europe, enzyme preparations are used.

For some researchers, adjuvants should always be added in olive oil technology, especially in pastes without adequate rheological properties for phase separation in malaxation. With adjuvants higher yield oil, and a great contribution to environment, as less $\mathrm{CO}_{2}$ is emitted, less water is consumed and all the

Table 8. Effect on yield improvement of some inorganic adjuvants (all trials performed in laboratorial Abencor extraction system).

\begin{tabular}{llcccc}
\hline Adjuvant & Cultivar & Ripening Index & Dose (\%) & Yield improvement (\%) & References \\
\hline $\mathrm{NaCl}$ & Picual & 1 & 2.5 & 21 & Pérez et al. (2008) \\
& Picual & 3 & 1.2 & 12 & Cruz et al. (2007) \\
& Arbequina & 2.2 & 2 & 14 & Canamasas and Raveti (2011) \\
$\mathrm{Si}_{8} \mathrm{O}_{20} \mathrm{Mg}_{6}(\mathrm{OH})_{4}(\mathrm{E} 553 \mathrm{~b})$ & Picual & 3 & 1.2 & 30 & Cruz et al. (2007) \\
& Coratina & 1.2 & 1.0 & 15 & Caponio et al. (2014a) \\
$\mathrm{Ca}\left(\mathrm{CO}_{3}\right)_{2}(\mathrm{E} 170)$ & Arbequina & 2.2 & 2 & 17 & Canamasas and Raveti (2011) \\
& Picual & 3 & 2 & 27 & Espinola et al. (2009) \\
& Arbequina & 2.2 & 2 & 11.5 & Canamasas and Raveti (2011) \\
& Arbequina & 4.5 & 2 & Espinola et al. (2009) \\
\hline
\end{tabular}


olive oil process is more profitable, without modification of olive oil characteristics.

The presence of $\mathrm{NaCl}$ in the olive pastes increases the density and the ionic strength of the aqueous phase, which may affect the solubility of certain compounds and may even modulate the activity of enzymes during the malaxation process. In addition, physico-chemical quality parameters of the VOOs were not significantly affected by the use of this adjuvant (Cruz et al., 2007). The addition of $\mathrm{NaCl}$ during the extraction process was positively correlated with the presence of $o$-diphenol compounds and the stability of the oils obtained. Furthermore, the use of $\mathrm{NaCl}$ resulted in a significant increase in the contents of $\beta$-carotene, lutein and chlorophylls $a$ and $b$ in the oils. The intensity of bitterness was slightly increased (Cruz et al., 2007).

Natural microtalc, which consists of hydrated magnesium silicate, $\mathrm{Si}_{8} \mathrm{O}_{20} \mathrm{Mg}_{6}(\mathrm{OH})_{4}$, is the most important adjuvant used by the olive oil industry, due to its hydrophobic surface and a platy particle shape that adsorbs the natural emulsifiers from the surface of the olive oil droplets. An increase in the amount of extracted oil can be observed with microtalc addition, since it promotes the coalescence of the small oil droplets making easier to separate the oil by centrifugation. Microtalc does not react with oils because of its crystalline structure and water affinity and it is easily removed by centrifugation together with olive pomace due to its high density $\left(2.72 \mathrm{~g} \mathrm{~cm}^{-3}\right)$ and water affinity (Espínola et al., 2009). The doses for talc addition referred in the literature for olive oil extraction are in the range between 0.5-2\% (Clodoveo, 2012; Servili et al., 2012; Uceda et al., 2006). However, excessive doses can have a negative effect on the extraction process, since the higher pomace oil content does not compensate for the oil content of wastewaters (Uceda et al., 2006). The particle size of the adjuvant could affect the oil yield: the extraction yield decreased as the particle size increased. For the same particle size, calcium carbonate was found to extract a greater oil amount than talc (Moya et al., 2010).

Results from the studies on talc addition show that this adjuvant does not exert any alteration on the VOO quality parameters prescribed by EEC Regulations and successive amendments (Ben-David et al., 2010; Caponio et al., 2014a; Carrapiso et al., 2013; Cert et al., 1996; Moya et al., 2010; Pita et al., 2011). VOO obtained with talc addition had a similar storage behavior, as those extracted without talc, during six month storage (Caponio et al., 2014a). Addition of talc in two phase decanter increased oxidative stability, but with no effect in total phenols (Cert et al., 1996). Talc addition ("Talcoliva”) in doses of $5.7 \%$ produced a reduction in tocopherols of about 12\% (Carrapiso et al., 2013).

Enzyme preparations are used as processing aids in several food industries. In olive oil technology, several promising studies were performed with the addition of blends of hemicellulases, cellulases and pectinases (Alba-Mendoza et al., 1987; Servili et al., 1992; Di Giovacchino, 1993; Ranalli and De Mattia, 1997; Ranalli et al., 1998; Ranalli et al., 2001b; Vierhuis et al., 2001; Servili et al., 2002b; Ranalli et al., 2003a; Ranalli et al., 2005; Aliakbarian et al., 2008; De Faveri et al., 2008;

Table 9. Commercial names, source, type of enzymes, applied doses and yield improvement in olive oil extraction.

\begin{tabular}{|c|c|c|c|c|c|}
\hline $\begin{array}{l}\text { Enzyme } \\
\text { commercial name }\end{array}$ & Type of enzymes & Source & Dose & $\begin{array}{l}\text { Yield improvement } \\
(\%)\end{array}$ & References \\
\hline Roehament 0 & $\begin{array}{l}\text { Glycosidases, cellulases and } \\
\text { hemicellulases }\end{array}$ & Aspergillus niger & $0.01-0.03 \%(w / w)$ & $0.3-11.6$ & Alba et al. (1987) \\
\hline Cytolase 0 & Pectinases, cellulases and hemicellulases & Aspergillus & $\begin{array}{l}0.3 \mathrm{~mL}\left(600 \mathrm{U} \mathrm{kg}^{-1} \text { of }\right. \\
\text { paste) }\end{array}$ & $3.2-8.3$ & Ranalli et al. (2001b) \\
\hline Bioliva & $\begin{array}{l}\text { Pectinases with small amounts of } \\
\text { cellulases and hemicellulases }\end{array}$ & Trichoderma & $600 \mathrm{U} \mathrm{kg}^{-1}$ olives & $0.8-1.2$ & Ranalli et al. (2003b) \\
\hline Rapidase adex D & Pectinases, cellulases and hemicellulases & Aspergillus sp. & $600 \mathrm{U} \mathrm{kg}^{-1}$ & $1.1-1.7$ & Ranalli et al. (2005) \\
\hline $\begin{array}{l}\text { Pectinex Ultra } \\
\quad S P-L\end{array}$ & $\begin{array}{l}\text { Polygalacturonase/pectin methyl } \\
\text { esterase/ Pectin lyase (ramno/ } \\
\text { hemicellulases) }\end{array}$ & Aspergillus aculeatus & $100-200 \mathrm{~mL} \mathrm{t}^{-1}$ paste & 22.7 (Barnea) & $\begin{array}{l}\text { Canamassas and } \\
\text { Ravetti (2011) }\end{array}$ \\
\hline NZ 33095 & $\begin{array}{l}\text { Polygalacturonase/pectin methyl } \\
\text { esterase/ Pectin lyase (ramno/ } \\
\text { hemicellulases) }\end{array}$ & Aspergillus niger & & 24.2 (Arbequina) & \\
\hline $\begin{array}{l}\text { NZ } 33095 / \\
\text { Celluclast } 1.5\end{array}$ & $\begin{array}{l}\text { Polygalacturonase/pectin methyl } \\
\text { esterase/ Pectin lyase (ramno/ } \\
\text { hemicellulases)/Cellulases }\end{array}$ & & & 53.4 (Barnea) & \\
\hline Viscozym L & $\begin{array}{l}\text { Polygalacturonase/pectin methyl } \\
\text { esterase/ Pectin lyase (ramno/ } \\
\text { hemicellulases)/ } \beta \text {-glucanases }\end{array}$ & & & $\begin{array}{l}28.0 \text { (Arbequina) } \\
24.7 \text { (Barnea) } \\
17.0 \text { (Arbequina) } \\
62.4 \text { (Barnea) } \\
16.0 \text { (Arbequina) }\end{array}$ & \\
\hline $\begin{array}{l}\text { Pectinex Ultra } \\
\quad \text { SP-L }\end{array}$ & Pectinases and hemicellulases & Aspergillus aculeatus & $0.02 \% \mathrm{v} / \mathrm{w}-0.04 \% \mathrm{v} / \mathrm{w}$ & $0.9-2.4$ & Najafian et al. (2009) \\
\hline Pectinase 1.06021 & & Aspergillus niger & $\begin{array}{l}\text { Activities }>26,000^{\mathrm{PG}} / \\
\quad \mathrm{mL}(\mathrm{pH} 3.5)\end{array}$ & & \\
\hline Olivex & Polygalacturonase & Aspergillus aculeatus & $\begin{array}{l}0.25 \text { and } 0.5 \mathrm{~mL} \mathrm{~kg}^{-1} \\
\left(26000 \mathrm{U} \mathrm{mL}^{-1}\right)\end{array}$ & 15 & Iconoumou et al. (2010) \\
\hline Glucanex & $\beta$-glucanase & Trichoderma sp. & $\begin{array}{l}0.03 \text { and } 0.06 \mathrm{~g} \mathrm{~kg}^{-1} \\
\left(300 \mathrm{U} \mathrm{mL}^{-1}\right)\end{array}$ & & \\
\hline Viscozymes & $\begin{array}{c}\text { arabanase, cellulase, } \beta \text {-glucanase, } \\
\text { hemicellulase and xylanase }\end{array}$ & Aspergillus niger & $0.015-0.030 w-\%$ & $49-69$ & Chih et al. (2012) \\
\hline Endozym Olea AS & $\begin{array}{l}\text { Pectinases with complementary } \\
\text { cellulases and hemicellulases activities }\end{array}$ & Aspergillus niger & $0.003-0.117 w-\%$ & $24-34$ & Peres et al. (2014) \\
\hline
\end{tabular}




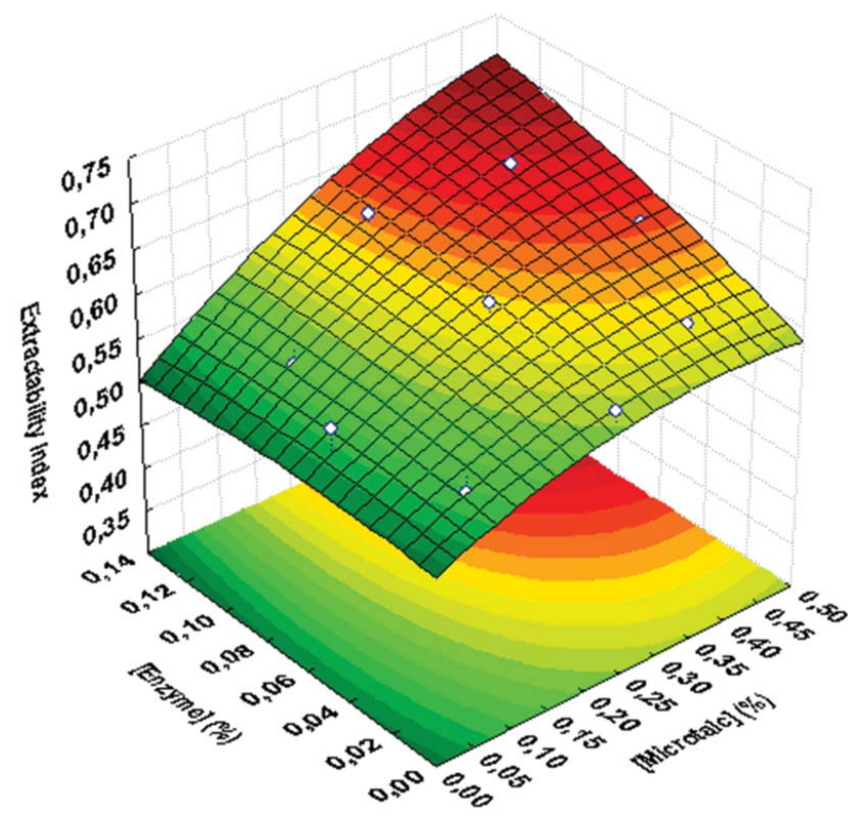

Figure 5. Response surface fitted to Extractability Index for Galega cv. (RI 6.5) as a function of enzyme (E) and microtalc (MT).

Najafian et al., 2009; Iconomou et al., 2010; Chih et al., 2012; Peres et al., 2014). Table 9 summarizes some studies performed with enzyme addition usually at the beginning of malaxation, main enzymatic activity, source, dose, and yield increase in olive oil extraction.

Usually, enzyme formulations increase both yields and quality level of VOO. Higher contents of phenols, volatile compounds and other key unsaponifiable components are present affecting positively the flavor, odor and shelf-life (Di Giovacchino, 1993; Ranalli and Ferrante, 1996; Ranalli and De Mattia, 1997; Ranalli et al., 1999; García et al., 2001b; Ranalli et al., 2003b; Ranalli et al., 2004; Aliakbarian et al., 2008; De Faveri et al., 2008). The addition of commercial enzyme preparations during malaxation can reduce the complexation of hydrophilic phenols with polysaccharides, increasing the concentration of free phenols in the olive paste (Vierhuis et al., 2001). However, due to their hydrophilicity, considerable amounts of these phenols may be lost in wastewaters. The variations in total phenols are quite dependent on the cultivar. Canamasas and Ravetti (2011) did not found any increase in phenol contents for "Barnea" cultivar when four different enzyme preparations were added at processing plant level, and lower phenol contents were achieved when Pectinex Ultra SP-L was added to Arbequina cultivar (Abencor trials). The study of evaluation the authenticity/genuinity of the VOO with enzymes addition

Table 10. Effect of microtalc $(0.4 \%(\mathrm{w} / \mathrm{w})$ and enzyme $(0.1 \%(\mathrm{v} / \mathrm{w}))$ simultaneous addition on sterol composition and FAEE for Galega Vulgar VOO.

\begin{tabular}{|c|c|c|}
\hline Experiment & Control & Microtalc + Enzyme \\
\hline Campesterol (\%) & 2.6 & 2.6 \\
\hline Stigmasterol (\%) & 0.32 & 0.30 \\
\hline$\beta$-sitosterol (\%) & 96.14 & 96.19 \\
\hline$\delta$-7-stigmastenol (\%) & 0.14 & 0.14 \\
\hline Total Sterols $\left(\mathrm{mg} \mathrm{kg}^{-1}\right)$ & 1332 & 1308 \\
\hline Erythrodiol+Uvaol (\%) & 0.88 & 0.77 \\
\hline FÁEE (mg kg $\left.{ }^{-1}\right)$ & 5.3 & 6.2 \\
\hline
\end{tabular}

shows that no relevant changes occur in compounds like triacylglycerols, waxes, sterols, and triterpene dialcohols (Ranalli et al., 2003b). The addition of the enzyme NZ 33095 promoted lower pyropheophytins values and higher 1,2-diacylglicerols contents in VOO (Canamasas and Ravetti, 2011).

The effect of the simultaneous addition of microtalc and enzymes on extraction yield and on olive oil quality and composition was studied by us at lab scale in an Abencor system. Results for Galega Vulgar (black fruits, ripening index (RI) of 6.5) showed that the best extraction conditions are for enzyme (Endozym olea) higher than $0.1 \%(\mathrm{v} / \mathrm{w})$ and microtalc (FC 8AW) $0.4-0.5 \%$ (w/w) (Fig. 5).

Since the first of March 2014, the European Union established the limit of $40 \mathrm{mg} \mathrm{kg}^{-1}$ of fatty acids ethyl esters (FAEE) for the EVOO category. Following the recommendations of IOC the limits for FAEE will be $30 \mathrm{mg} \mathrm{kg}^{-1}$ in 2015/16 and thereafter (Reg (UE) 1348/2013). So, it is important to evaluate the effect of talc or enzyme addition on the presence of these compounds that result from inadequate practices during olive oil extraction and from using poor quality olives (Giuffrè, 2014). Table 10 shows that no effect in sterols and FAEE content was observed ( $\mathrm{t}$ test, $p>0.05$ ) after microtalc (FC 8-AW) and enzyme (Endozym olea) addition in Galega Vulgar (RI = 6.5).

In two-phase decanters water addition in malaxation is considered to have a great impact in pastes extractability, when olive moisture content is very low (lower than 45\%). Consequently, in these systems water addition is considered as an adjuvant.

\section{Solid-liquid extraction}

The extraction system (pressure or centrifugation) plays an important role in the presence of volatile and phenolic compounds in VOO. All systems may provide extra VOO if olive fruits are of good quality, but the centrifugation system helps to avoid or reduce the risk of sensory defects ascribed to the use of recycled mats in pressure systems (Di Giovacchino et al., 2002). The solid/liquid pressure method is only a valid form of producing high-quality olive oil, if after each extraction, the mat disks are properly cleaned in order to avoid the development of unpleasant odor notes arising from endogenous or microbial enzymatic activities in pastes (Angerosa et al., 2004). In this extraction method, the addition of water is minimal when compared to the continuous system. Thus, the hydrophilic phenol compounds are usually maintained in VOO. On the contrary, the exposition of olive paste to the action of oxygen and light is high.

Nowadays, the majority of VOO in the market is currently extracted by centrifugation. The first operating patents, including the patent by Corteggiani, date back to 1956, followed by the manufacture of olive oil machines by new companies in the early sixties. In 1965, Alfa -Laval Company constructed the "Centriolive Plant", with a three phase "De-Sludger" centrifuge (Ranalli and Martinelli, 1995). This machine, called decanter, consists of a drum containing a cylindrical and a conical part with a horizontal axis, inside which an additional cylinder worm is placed, which acts as a screw conveyor. The differential speed of the latter is slower than that of the outer drum, in 
Table 11. Differences in chemical compounds of VoO obtained from three and two phase decanters.

\begin{tabular}{lll}
\hline Three-phase Decanter & Two-phase Decanter & \multicolumn{1}{c}{ References } \\
\hline+ pigments & + trans-2-hexenal & $\begin{array}{c}\text { (Di Giovacchino et al., 2002; } \\
\text { Aparicio e Luna, 2002; } \\
\text { Kalogeropoulos et al., } \\
\text { 2014) }\end{array}$ \\
$\begin{array}{c}\text { aliphatic and } \\
\text { triterpenic alcohols }\end{array}$ & + total phenols & \\
+ steroid hydrocarbons & + orthodiphenols \\
+ waxes & + hydroxytyrosol \\
& + tocopherols \\
& + reducing power & \\
\hline
\end{tabular}

order to discharge the solid part. The three-phase decanter was till 1992 the only horizontal centrifugation system to perform solid/liquid separation.

In the last decades, this extraction system was modified in order to reduce the amount of water used during the process. According to Servili et al. (2012) the decanters can nowadays be classified as follows:

(a) traditional three phase decanters with water addition between 0.5 and $1 \mathrm{~m}^{3}$ per $\mathrm{t}$;

(b) new three phase decanters, maximum level of water addition 0.2 and $0.3 \mathrm{~m}^{3}$ per $\mathrm{t}$;

(c) two phase decanters that can work without water addition.

In the traditional three-phase decanters, where the oil is separated both from the vegetation water and from the pomace, the humidity level of the pastes must be fixed between 50 and $55 \%$ in order to reduce their viscosity. In addition to the high amounts of vegetation water produced, this implies a decrease in the oil quality, mainly due to the removal of hydrophilic phenol compounds of VOO (De Stefano et al., 1999; Di Giovacchino et al., 2002; Servili et al., 2004). The addition of warm water, used to dilute the olive pastes in these three-phases decanters, can explain the decrease in C6 alcohols, hexan-1-ol, and trans-2-hexen-1-ol when compared to oils obtained in pressing systems (Angerosa et al., 2004).

The evolution of this technology for two and three-phase decanters with low water consumption results in VOO with phenol contents higher than those extracted by the traditional centrifugation process. This is mainly due to a decrease in hydrophilic phenolic compounds in the vegetation water (Aparicio and Luna, 2002; Gimeno et al., 2002; Servili et al., 2009). Moreover, the two-phases centrifugal decanters, operating without adding water (or only a minimal amount of water) to olive paste, save heat, energy and the oils obtained are more fruity and have a higher content of antioxidants (Di Giovacchino et al., 2002; Kalogeropoulos et al., 2014). Table 11 summarizes the main differences in some compounds present in VOO obtained by three or two phase decanters.

The type of oil extraction plant (three or two phases) markedly affects the level of the hydrophilic phenols in the oil and consequently the related sensory attributes of bitter, pungency and astringency, as well as the level of autoxidation hydrocarbons, esters from fermentations, keto acids derivatives, and all the LOX derived groups, except for C6 aldehydes (Pastore et al., 2014). Drum speed can also affect phenol and volatile contents of VOO. The oils extracted at lower drum speeds are usually bitterer and show higher peroxide and $\mathrm{K}_{270}$ values, as well as higher amounts of volatile compounds related to aldehydes oxidation (Caponio et al., 2014b)

Whatever the centrifugal technology used, pomace has always a high level of oil. Pomace olive oil creates damages to the image of the $\mathrm{VOO}$ and competes with VOO determining a detrimental effect on the prices and on producer incomes (Clodoveo et al., 2014). This will be overcome by the introduction in 2012 by Pieralisi Company, of a multi-phase decanter, the "Leopard two-phase decanter," that changes the byproducts, producing a dehydrated husk similar to the one coming from a three-phase decanter; it also separates the pulp from the husk, obtaining an ingredient for composting or animal feeding.

\section{Liquid/liquid separation}

The oil phases are further clarified in an automated discharge vertical disk centrifuge by the addition of tepid water. Vertical centrifugation removes the residual water and the solid impurities from the oil, reducing the VOO moisture content to a mean value of about $0.18 \%$ (Masella et al., 2009). However, the addition of water reduces the content of hydrophilic phenols. Also, vertical centrifugation causes a strong oxygenation of the VOO resulting in a marked increase of dissolved oxygen concentration (Masella et al., 2009; Parenti et al., 2007). This condition can lead to a noticeable shortening of the oil shelf-life as a consequence of accelerated oxidation (Clodoveo et al., 2014). A decrease of C6 and C5 volatile compounds has been observed during the vertical centrifugation as compared to noncentrifuged VOO (Masella et al., 2009).

Since the vertical centrifugation is the processing step that mainly contributes to the oil oxygenation, blanketing the vertical separator with an inert gas would be a feasible way to reduce the dissolved oxygen concentration. VOO vertical centrifugation under inert gas promotes a strong reduction of the oil oxygenation, in terms of reduced dissolved oxygen concentration and oxidative indexes (peroxide value and $\mathrm{K}_{232}$ ). Moreover, minor compounds such as chlorophyll, total phenols and volatile compounds are not affected by this treatment (Masella et al., 2012).

\section{Storage of olive oils}

The storage of olive oils in stainless steel tanks after extraction is actually a common practice all over the world. The maintenance of a constant temperature inside the tank between 12 and $22^{\circ} \mathrm{C}$, before bottling, is a recommended practice (IOC, 2006).

Important losses of chlorophyll, carotenoids, and total phenols in oils occur during the storage period due to oxidation (Psomiadou and Tsimidou, 2002). A significant decrease in secoiridoid derivatives and 3,4-DHPEA-AC was observed after a year storage period, while lignans were the most stable phenol compounds and $\alpha$-tocopherol disappeared after the storage period (Morelló et al., 2004). Similarly, the main change found in the phenol composition of virgin olive oils of Arbequina, Hojiblanca, and Picual varieties, during storage in darkness at 
$30^{\circ} \mathrm{C}$ was the hydrolysis of the secoiridoid aglycons. This reaction gave rise to an increase in hydroxytyrosol and tyrosol in VOO (Brenes et al., 2001).

Volatile compounds, responsible for off-flavors in VOO, such as hexanal, octane and other C8 and C9 compounds, are formed through nonenzymatic oxidation during $\mathrm{VOO}$ storage, favored by high temperatures, oxygen, light, and pro-oxidants compounds. When VOO was stored in contact with air the levels of some negative sensory components, such as penten-3-ol and hexanal increased while other compounds with positive notes, like trans-2hexenal were reduced (Stefanoudaki et al., 2010). Recently, the use of stripping nitrogen to remove the dissolved oxygen from the oil, immediately after extraction has also been suggested, in order to increase VOO shelf life (Masella et al., 2010).

Therefore, the main deteriorative reaction that occurs during storage is oxidation but the endogenous enzymatic activities contained in the cloudy phase can modify the olive oil phenolic composition (Taticchi et al., 2014). Cloudy, or veiled VOO contains polyphenols, phospholipids, and sugars, but it can also contain hydrolytic and oxidative enzymes, such as lipases, LOX, and polyphenol oxidases. These enzymes may reduce the "pungent" and "bitter" sensory notes, the intensity of which is strictly linked to the content of aglycon secoiridoids, and, at the same time, can produce olfactory and taste defects. Consequently, the olive oil profile changes during its storage, due to the simultaneous drastic reduction in compounds by the LOX pathway and to the formation of new volatile compounds, responsible for some common defects as "rancid," "cucumber" and "muddy sediment"(Angerosa et al., 2004; Aparicio et al., 2000; Morales et al., 1997). This is accompanied by the increase in saturated aldehydes nonanal and hexanal, coming from the oxidation process (Angerosa et al., 2004).

The racking operation generally leads to a relative decrease of $\mathrm{C} 6$ volatiles vs. $\mathrm{C} 5$ components, what gives to the resulting oils a more intense bitter character. Moreover, minor alcohols with odor activity levels (OAVs) higher than 0.2, namely 2-methyl-1-butanol and 3-methyl-1-butanol (with whiskey-like and spicy notes), have a slight trend to increase while minor aldehydes with OAVs that can be as higher as 150 , such as 2-methyl-butanal and 3-methyl-butanal (with malty nuances), can be much higher in the oils after racking (ReboredoRodríguez et al., 2013).

\section{Filtration of VOO}

The filtration process of VOO is a procedure carried out in two steps: first, the suspended solids are removed, and after water traces are removed to give the oil a brilliant aspect (LópezVillalta, 2008). Together with water, enzymes are also removed from VOO. Thus, VOO phenol content is maintained, which contributes to its stabilization during storage. Generally, organic or inorganic materials are used in conjunction with a variety of filtration equipment to enhance or enable the separation of suspended solids and water from the oil by filtration (Lozano-Sánchez et al., 2010).

Veiled oils were found to have longer induction periods, compared to filtered ones (Lercker et al., 1994). It appears that the material in suspension-dispersion that "veils" the oil plays an important role against oxidation, although there is little evidence concerning the chemical nature of the compounds participating in the stable dispersion system. Higher total phenol content in veiled oils in relation to filtered ones may partly explain the higher stability of these VOO (Tsimidou et al., 2005).

During filtration, a loss of phenols occurs favoring a reduction of oxidative stability. However, the presence of sediment from unfiltered VOO during its storage, can lead to the production of the typical "muddy" defect, probably due to a butyric type fermentation process (Servili et al., 2004). Therefore, the filtration of VOO can avoid the fermentation of sugars or proteins producing volatile compounds responsible for this sensory defect (Clodoveo et al., 2014).

Other possible explanation might be the presence of emulsifiers (e.g. phospholipids) in higher amounts in cloudy VOO than in filtered ones (Koidis and Boskou, 2006).

It has also been suggested that small quantities of proteins may contribute to the higher oxidative stability of unfiltered olive oils (Zamora et al., 2002). There is a discrepancy in the literature concerning the level of proteins and values varying from 0.1 to $400 \mathrm{mg} \mathrm{kg}^{-1}$ have been reported (Georgalaki et al., 1998). Koidis and Boskou (2006) demonstrated that the level of proteins in cloudy olive oil is very low, not exceeding $2.5 \mathrm{mg}$ $\mathrm{kg}^{-1}$ oil. This indicates that a great antioxidant activity cannot be expected from proteins in the presence of strong antioxidants ( $\alpha$-tocopherol, $o$-diphenols) at much higher concentrations. A lipoxygenase activity has also been detected in freshly prepared olive oil (Georgalaki et al., 1998).

Although the presence of a small quantity of water in nonfiltered oils, a favorable condition for enzymatic activity, these oils have higher oxidative stabilities. Boskou (2006) assumed that the polar phenol compounds present not only act as primary antioxidants, but also as inhibitors of oxidizing enzymes.

Ciafardini and Zullo (2002) identified yeasts as the dominant microbial population in nonfiltered VOO during the sedimentation period. The authors suggested filtration as a mean to ensure high quality extra virgin olive oil, despite the serious reduction in polar phenols.

Filtration and especially dehydration could help to prolong the shelf life of high-quality and less stable olive oils like those obtained from the Arbequina cultivar (Fregapane et al., 2006). Several results show that the impact of filtration depends on each monovariety olive oil. Thus it could be useful to develop targeted technologies for specific VOO quality improvement (Bubola et al., 2012).

\section{Conclusions}

In the last years, the focus of innovation in olive oil technology has been more and more on promoting the aspects that are related with health issues and sensory quality of VOO. In fact, the consumer demand shows an increasing interest towards a product with hedonistic and healthy value. Olive oil extraction is not just a mechanical process. Several biochemical and chemical reactions can occur, from the ripening of the drupes till the end of oil storage. Therefore, it is very important to have a better knowledge of all the factors that influence VOO extraction 
system in order to develop useful solutions to increase oil yield, process efficiency and quality.

A better understanding of the behavior of endogenous enzymes as well as the use of adjuvants during olive oil extraction, may allow establishing specific technological conditions for each cultivar or blend of cultivars. Such studies are multidisciplinary joining backgrounds on biochemistry, chemistry, technology and physics, in a joint effort to bring VOO with high nutritional value and sensory balance.

\section{Acknowledgments}

The authors are very grateful to Rita Pereira for the graphical composition of Figs. 1, 2, and 4.

\section{Funding}

This study was supported by the national funding of FCT - Fundação para a Ciência e a Tecnologia, Portugal, to the research unit of LEAF (UID/ AGR/04129/2013).

\section{References}

Alba, J., Izquierdo, J. R., Gutiérrez, F. and Vossen, P. (2008). Aceite de Oliva Virgen. Análisis Sensorial, 2nd ed. Editorial Agrícola Española, S. A., Madrid.

Alba Mendoza, J., Ruiz Gomez, A. and Hidalgo Casado, F. (1990). Utilización de enzimas en la extracción del aceite de oliva (The use of enzymes in olive oil extraction). Alimentación, Equipos y Tecnología. 9:63-78.

Alba-Mendoza, J., Moyano Pérez, M. J., Martinéz Román, F. and Hidalgo Casado, F. (2005). Influencia de la granulometria y del contenido de carbonatos del talco sobre el rendimiento en aceite de oliva virgen. (Effect of particle size and carbonate content of talc in virgin olive oil extraction yield). In: XII Simposium Cientifico-Técnico Expoliva 2005, Jaen.

Alba-Mendoza, J., Ruiz-Gomez, M. A., Prieto-Gonzalez, M. C. and Gutierrez-Rosales, F. (1987). Efficacy of the enzyme preparation 'Roehament $\mathrm{O}$ ' in the technology of olive-oil. Composition and organoleptic evaluation of the oil produced. Grasas Y Aceites. 38:271-277.

Aliakbarian, B., De Faveri, D., Converti, A. and Perego, P. (2008). Optimisation of olive oil extraction by means of enzyme processing aids using response surface methodology. Biochem. Eng. J. 42:34-40.

Aliakbarian, B., Dehghani, F. and Perego, P. (2009). The effect of citric acid on the phenolic contents of olive oil. Food Chem. 116:617-623.

Amiot, M. J. (2014). Olive oil and health effects: From epidemiological studies to the molecular mechanisms of phenolic fraction. OCL. 21: D512.

Amirante, P., Arena, G., Clodoveo, M. L., Dugo, G., Leone, A., Lo Turco, V., Pollicino, D. and Tamborrino, A. (2007). Virgin olive oil production from de-stoned pastes: A new technology to improve the shelf life of the product. Italian J. Food Sci. 19:116-120.

Amirante, P., Clodoveo, M. L., Dugo, G., Leone, A. and Tamborrino, A. (2006). Advance technology in virgin olive oil production from traditional and de-stoned pastes: Influence of the introduction of a heat exchanger on oil quality. Food Chem. 98:797-805.

Amirante, P., Clodoveo, M. L., Tamborrino, A., Leone, A. and Paice, A. G. (2010). Influence of the crushing system: Phenol content in virgin olive oil produced from whole and de-stoned pastes. In: Olives and Olive Oil in Health and Disease Prevention, pp. 69-76. Victor, R. P. and Watson, R. R., Eds., Elsevier Inc.

Angerosa, F. (2000). Sensory Quality of Olive oils. In: Handbook of Olive Oil, pp. 355-392. Harwood, J. and Aparicio, R., Eds., Aspen Publishers, Maryland.
Angerosa, F. (2002). Influence of volatile compounds on virgin olive oil quality evaluated by analytical approaches and sensor panels. Eur. J. Lipid Sci. Technol. 104:639-660.

Angerosa, F. and Basti, C. (2003). The volatile composition of samples from the blend of monovarietal olive oils and from the processing of mixtures of olive fruits. Eur. J. Lipid Sci. Technol. 105:327-332.

Angerosa, F., Basti, C. and Vito, R. (1999). Virgin olive oil volatile compounds from lipoxygenase pathway and characterization of some italian cultivars. J. Agric. Food Chem. 47:836-839.

Angerosa, F., Mostallino, R., Basti, C. and Vito, R. (2000). Virgin olive oil odour notes: Their relationships with volatile compounds from the lipoxygenase pathway and secoiridoid compounds. Food Chem. 68:283-287.

Angerosa, F., Mostallino, R., Basti, C. and Vito, R. (2001). Influence of malaxation temperature and time on the quality of virgin olive oils. Food Chem. 72:19-28.

Angerosa, F., Servili, M., Selvaggini, R., Taticchi, A., Esposto, S. and Montedoro, G. (2004). Volatile compounds in virgin olive oil: Occurrence and their relationship with the quality. J. Chromatogr. A 1054:17-31.

Anthon, G. E. and Barrett, D. M. (2003). Thermal inactivation of lipoxygenase and hydroperoxytrienoic acid lyase in tomatoes. Food Chem. 81:275-279.

Aparicio, R. and Luna, G. (2002). Characterisation of monovarietal virgin olive oils. Eur. J. Lipid Sci. Technol. 104:614-627.

Aparicio, R. and Morales, M. T. (1998). Characterization of olive ripeness by green aroma compounds of virgin olive oil. J. Agric. Food Chem. 46:1116-1122.

Aparicio, R., Morales, M. T. and García-González, D. L. (2012). Towards new analyses of aroma and volatiles to understand sensory perception of olive oil. Eur. J. Lipid Sci. Technol. 114:1114-1125.

Aparicio, R., Rocha, S. M., Delgadillo, I. and Morales, M. T. (2000). Detection of rancid defect in virgin olive oil by the electronic nose. J. Agric. Food Chem. 48:853-860.

Belitz, H., Grosh, D. W. and Shieberle, P. (2009). Food Chemistry. Springer-Verlag Berlin Heidelberg, Leipzig.

Ben-David, E., Kerem, Z., Zipori, I., Weissbein, S., Basheer, L., Bustan, A. and Dag, A. (2010). Optimization of the Abencor system to extract olive oil from irrigated orchards. Eur. J. Lipid Sci. Technol. 112:11581165.

Berenguer, M. J., Vossen, P. M., Grattan, S. R., Connell, J. H. and Polito, V. S. (2006). Tree irrigation levels for optimum chemical and sensory properties of olive oil. HortScience. 41:427-432.

Berlioz, B., Cordella, C., Cavalli, J.-F., Lizzani-Cuvelier, L., Loiseau, A.-M. and Fernandez, X. (2006). Comparison of the amounts of volatile compounds in French Protected Designation of Origin virgin olive oils. J. Agric. Food Chem. 54:10092-10101.

Boselli, E., Di Lecce, G., Strabbioli, R., Pieralisi, G. and Frega, N. G. (2009). Are virgin olive oils obtained below $27^{\circ} \mathrm{C}$ better than those produced at higher temperatures? LWT - Food Sci. Technol. 42:748-757.

Boskou, D. (2006). Storage and packing. In: Olive Oil Chemistry and Technology, 2nd ed., pp 233-242. Boskou, D., Ed., AOCS Press, Ilinois.

Brenes, M., García, A., García, P. and Garrido, A. (2001). Acid hydrolysis of secoiridoid aglycons during storage of virgin olive oil. J. Agric. Food Chem. 49:5609-5614.

Brenes-Balbuena, M., Garcia-Garcia, P. and Garrido-Fernandez, A. (1992). Phenolic compounds related to the black color formed during the processing of ripe olives. J. Agric. Food Chem. 40:1192-1196.

Bubola, K. B., Koprivnjak, O. and Sladonja, B. (2012). Influence of filtration on volatile compounds and sensory profile of virgin olive oils. Food Chem. 132:98-103.

Campeol, E., Flamini, G., Cioni, P. L., Morelli, I., Cremonini, R. and Ceccarini, L. (2003). Volatile fractions from three cultivars of Olea europaea L. collected in two different seasons. J. Agric. Food Chem. 51:1994-1999.

Canamasas, P. and Ravetti, L. (2011). Evaluation of processing aids for olive oil extraction and quality improvement. Rural Industries Research and Development Corporation., Canberra.

Caponio, F., Monteleone, J. I., Martellini, G., Summo, C., Paradiso, V. M. and Pasqualone, A. (2014a). Effect of talc addition on the extraction yield and quality of extra virgin olive oils from coratina cultivar after production and during storage. J. Oleo Sci. 63:1125-1132. 
Caponio, F., Summo, C., Paradiso, V. M. and Pasqualone, A. (2014b). Influence of decanter working parameters on the extra virgin olive oil quality. Eur. J. Lipid Sci. Technol. 116:1626-1633.

Carrapiso, A. I., García, A., Petrón, M. J. and Martín, L. (2013). Effect of talc and water addition on olive oil quality and antioxidants. Eur. J. Lipid Sci. Technol. 115:583-588.

Cavalli, J.-F., Fernandez, X., Lizzani-Cuvelier, L. and Loiseau, A.-M. (2004). Characterization of volatile compounds of French and Spanish virgin olive oils by HS-SPME: Identification of quality-freshness markers. Food Chem. 88:151-157.

Cerretani, L., Baccouri, O. and Bendini, A. (2008a). Improving of oxidative stability and nutritional properties of virgin olive oils by fruit de-stoning. Agro Food Industry Hi-Tech. 19:21-23.

Cerretani, L., Bendini, A., Del Caro, A., Piga, A., Vacca, V., Caboni, M. F. and Toschi, T. G. (2006). Preliminary characterisation of virgin olive oils obtained from different cultivars in Sardinia. Eur. Food Res. Technol. 222:354-361.

Cerretani, L., Bendini, A., Poerio, A. and Toschi, T. G. (2008b). Citric acid as co-adjuvant: Improvement of the antioxidant activity of edible olive oils. Agro Food Industry Hi-Tech. 19:64-66.

Cerretani, L., Salvador, M. D., Bendini, A. and Fregapane, G. (2008c). Relationship between sensory evaluation performed by italian and spanish official panels and volatile and phenolic profiles of virgin olive oils. Chem. Percept. 1:258-267.

Cert, A., Alba, J., Leon Camacho, M., Moreda, W. and PerezCamino, M. C. (1996). Effects of talc addition and operating mode on the quality and oxidative stability of virgin olive oils obtained by centrifugation. $J$. Agric. Food Chem. 44:3930-3934.

Chiacchierini, E., Mele, G., Restuccia, D. and Vinci, G. (2007). Impact evaluation of innovative and sustainable extraction technologies on olive oil quality. Trend Food Sci. Technol. 18:299-305.

Chih, H. J., James, A. P., Jayasena, V. and Dhaliwal, S. S. (2012). Addition of enzymes complex during olive oil extraction improves oil recovery and bioactivity of Western Australian Frantoio olive oil. Int. J. Food Sci. Technol. 47:1222-1228.

Ciafardini, G. and Zullo, B. A. (2002). Microbiological activity in stored olive oil. Int. J. Food Microbiol. 75:111-118.

Ciafardini, G., Zullo, B. A., Cioccia, G. and Iride, A. (2006a). Lipolytic activity of Williopsis californica and Saccharomyces cerevisiae in extra virgin olive oil. Int. J. Food Microbiol. 107:27-32.

Ciafardini, G., Zullo, B. A. and Iride, A. (2006b). Lipase production by yeasts from extra virgin olive oil. Food Microbiol. 23:60-67.

Clodoveo, M. L. (2012). Malaxation: Influence on virgin olive oil quality. Past, present and future - An overview. Trend Food Sci. Technol. 25:13-23.

Clodoveo, M. L. and Hbaieb, R. H. (2013). Beyond the traditional virgin olive oil extraction systems: Searching innovative and sustainable plant engineering solutions. Food Res. Int. 54:1926-1933.

Clodoveo, M. L. (2013). WIPO Patent No 2013076592. World Intellectual Property Organization, Geneva, Switzerland.

Clodoveo, M. L., Hbaieb, R. H., Kotti, F., Mugnozza, G. S. and Gargouri, M. (2014). Mechanical strategies to increase nutritional and sensory quality of virgin olive oil by modulating the endogenous enzyme activities. Compr. Rev. Food Sci. Food Saf. 13:135-154.

Coimbra, M. A., Delgadillo, I., Waldron, K. W. and Selvendran, R. R. (1996). Isolation and analysis of cell wall polymers from olive pulp. In: Plant Cell Wall Analysis, pp. 19-44. Linskens, H. and Jackson, J., Eds., Springer, Berlin, Heidelberg.

Coimbra, M. A., Waldron, K. W. and Selvendran, R. R. (1994). Isolation and characterisation of cell wall polymers from olive pulp (Olea europaea L.). Carbohydr. Res. 252:245-262.

Criado, M., Morelló, J., Motilva, M. and Romero, M. (2004). Effect of growing area on pigment and phenolic fractions of virgin olive oils of the arbequina variety in Spain. J. Am. Oil Chem. Soc. 81:633640 .

Cruz, S., Yousfi, K., Pérez, A. G., Mariscal, C. and Garcia, J. M. (2007). Salt improves physical extraction of olive oil. Eur. Food Res. Technol. 225:359-365.

De Faveri, D., Aliakbarian, B., Avogadro, M., Perego, P. and Converti, A. (2008). Improvement of olive oil phenolics content by means of enzyme formulations: Effect of different enzyme activities and levels. Biochem. Eng. J. 41:149-156.

De Stefano, G., Piacquadio, P., Servili, M., Di Giovacchino, L. and Sciancalepore, V. (1999). Effect of extraction systems on the phenolic composition of virgin olive oils. Lipid/Fett. 101:328-332.

Di Giovacchino, L. (1993). L'impiego dei preparati enzimatici nella estrazione dell'olio dalle olive con i sistemi continui di centrifugazione. I: Risultati di esperienze pluriennali (The use of enzyme preparations in olive oil extraction in continuous centrifugation systems. I: Results of pluriannual experiments). Rivista Italiana delle Sostanze Grasse. 70:279-287.

Di Giovacchino, L., Sestili, S. and Di Vincenzo, D. (2002). Influence of olive processing on virgin olive oil quality. Eur. J. Lipid Sci. Technol. 104:587-601.

Dierkes, G., Bongartz, A., Guth, H. and Hayen, H. (2011). Quality evaluation of olive oil by statistical analysis of multicomponent stable isotope dilution assay data of aroma active compounds. J. Agric. Food Chem. 60:394-401.

Domingues, A., Peres, M. F., Ferreira, A., Vitorino, M. C., Gouveia-Martins, C. and Madeira, C. (2009). A moenda da azeitona e as características fisico-químicas dos azeites virgens (Olive milling and the physicochemical properties of virgin olive oils). Actas Portuguesas de Horticultura 198-202.

Duarte-Costa, H. M. P. d.-L. and Sameiro, M. E. M. d.-M. S. (1978). Quality of olive oil extracted using enzyme preparations. Boletim Instituto do Azeite e Produtos Oleaginosos. 6:25-38.

Ebrahimzadeh, H., Motamed, N., Rastgar-Jazii, F., Montasser-Kouhsari, S. and Shokraii, E. H. (2003). Oxidative enzyme activities and soluble protein content in leaves and fruits of olives during ripening. J. Food Biochem. 27:181-196.

EC. (2012). Economic analysis of the olive sector. European Commission, Directorate-General for Agriculture and Rural Development. Available from http://ec.europa.eu/agriculture/olive-oil/economic-analysis_en.pdf

El Riachy, M., Priego-Capote, F., Rallo, L., Luque-de Castro, M. D. and León, L. (2013). Phenolic composition of virgin olive oils in cultivars for narrow hedgerow olive orchards. Eur. J. Lipid Sci. Technol. 115:800-810.

Esen, A. (2003). $\beta$-glucosidase. In: Handbook of Food Enzymology. Whitaker, J. R., Voragen, A. G. J. and Wong, D. W. S., Eds., Marcel Dekker, Inc., New York.

Espínola, F., Moya, M., Fernández, D. G. and Castro, E. (2009). Improved extraction of virgin olive oil using calcium carbonate as coadjuvant extractant. J. Food Eng. 92:112-118.

Espínola, F., Moya, M., Fernández, D. G. and Castro, E. (2011). Modelling of virgin olive oil extraction using response surface methodology. Int. J. Food Sci. Technol. 46:2576-2583.

Esti, M., Cinquanta, L. and La Notte, E. (1998). Phenolic compounds in different olive varieties. J. Agric. Food Chem. 46:32-35.

Fadiloğlu, S. and Söylemez, Z. (1997). Kinetics of lipase-catalyzed hydrolysis of olive oil. Food Res. Int. 30:171-175.

Fakas, S., Kefalogianni, I., Makri, A., Tsoumpeli, G., Rouni, G., Gardeli, C., Papanikolaou, S. and Aggelis, G. (2010). Characterization of olive fruit microflora and its effect on olive oil volatile compounds biogenesis. Eur. J. Lipid Sci. Technol. 112:1024-1032.

Fernández-Bolaños, J., Heredia, A., Vioque, B., Castellano, J. M. and Guillén, R. (1997). Changes in cell-wall-degrading enzyme activities in stored olives in relation to respiration and ethylene production. Journal Zeitschrift für Lebensmitteluntersuchung und -Forschung A. 204:14314630.

Fernández-Bolaños, J., Rodríguez, R., Guillén, R., Jiménez, A. and Heredia, A. (1995). Activity of cell wall-associated enzymes in ripening olive fruit. Physiol. Plantarum. 93:651-658.

Fregapane, G., Lavelli, V., León, S., Kapuralin, J. and Salvador, M. D. (2006). Effect of filtration on virgin olive oil stability during storage. Eur. J. Lipid Sci. Technol. 108:134-142.

Fregapane, G. and Salvador, M. D. (2013). Production of superior quality extra virgin olive oil modulating the content and profile of its minor components. Food Res. Int. 54:1907-1914.

García, A., Brenes, M., Martínez, F., Alba, J., García, P. and Garrido, A. (2001a). High-performance liquid chromatography evaluation of 
phenols in virgin olive oil during extraction at laboratory and industrial scale. J. Am. Oil Chem. Soc. 78:625-629.

García, A., Brenes, M., Moyano, M. J., Alba, J., García, P. and Garrido, A. (2001b). Improvement of phenolic compound content in virgin olive oils by using enzymes during malaxation. J. Food Eng. 48:189-194.

Garcia, J. M., Yousfi, K., Mateos, R., Olmo, M. and Cert, A. (2001). Reduction of oil bitterness by heating of olive (Olea europaea) fruits. J. Agric. Food Chem. 49:4231-4235.

García-González, D. L. and Aparicio, R. (2002). Detection of vinegary defect in virgin olive oils by metal oxide sensors. J. Agric. Food Chem. 50:1809-1814.

García-Gonzaález, D. L. and Aparicio, R. (2010). Research in olive oil: Challenges for the near future. J. Agric. Food Chem. 58:12569-12577.

García-González, D. L., Tena, N. and Aparicio, R. (2007). Characterization of olive paste volatiles to predict the sensory quality of virgin olive oil. Eur. J. Lipid Sci. Technol. 109:663-672.

García-Rodríguez, R., Romero-Segura, C., Sanz, C. and Pérez, A. G. (2015). Modulating oxidoreductase activity modifies the phenolic content of virgin olive oil. Food Chem. 171:364-369.

García-Rodríguez, R., Romero-Segura, C., Sanz, C., Sánchez-Ortiz, A. and Pérez, A. G. (2011). Role of polyphenol oxidase and peroxidase in shaping the phenolic profile of virgin olive oil. Food Res. Int. 44:629-635.

Georgalaki, M., Sotiroudis, T. and Xenakis, A. (1998). The presence of oxidizing enzyme activities in virgin olive oil. J. Am. Oil Chem. Soc. 75:155-159.

Gimeno, E., Castellote, A. I., Lamuela-Raventós, R. M., De la Torre, M. C. and López-Sabater, M. C. (2002). The effects of harvest and extraction methods on the antioxidant content (phenolics, $\alpha$-tocopherol, and $\beta$-carotene) in virgin olive oil. Food Chem. 78:207-211.

Giuffrè, A. M. (2014). Wax ester variation in olive oils produced in Calabria (Southern Italy) during olive ripening. J. Am. Oil Chem. Soc. 1-12.

Gómez-Rico, A., Salvador, M. D., Moriana, A., Pérez, D., Olmedilla, N., Ribas, F. and Fregapane, G. (2007). Influence of different irrigation strategies in a traditional Cornicabra cv. olive orchard on virgin olive oil composition and quality. Food Chem. 100:568-578.

Goupy, P., Fleuriet, A., Amiot, M. J. and Macheix, J. J. (1991). Enzymic browning, oleuropein content, and diphenol oxidase activity in olive cultivars (Olea europaea L.). J. Agric. Food Chem. 39:92-95.

Hadj-Taieb, N., Ayadi, M., Trigui, S., Bouabdallah, F. and Gargouri, A. (2002). Hyperproduction of pectinase activities by a fully constitutive mutant (CT1) of Penicillium occitanis. Enzyme Microbial Technol. 30:662-666.

Hatanaka, A. (1996). The fresh green odor emmited by plants. Food Rev. Int. 12:303-350.

Hbaieb, R. H., Kotti, F., García-Rodríguez, R., Gargouri, M., Sanz, C. and Pérez, A. G. (2015). Monitoring endogenous enzymes during olive fruit ripening and storage: Correlation with virgin olive oil phenolic profiles. Food Chem. 174:240-247.

Heredia, A., Guillén, R., Jiménez, A. and Fernández-Bolaños, J. (1993). Activity of glycosidases during development and ripening of olive fruit. Journal Zeitschrift für Lebensmitteluntersuchung und -Forschung A. 196:147-151.

Iconomou, D., Arapoglou, D. and Israilides, C. (2010). Improvement of phenolic antioxidants and quality characteristics of virgin olive oil with the addition of enzymes and nitrogen during olive paste processing. Grasas Y Aceites. 61:303-311.

Inarejos-García, A. M., Gómez-Rico, A., Salvador, M. D. and Fregapane, G. (2009). Influence of malaxation conditions on virgin olive oil yield, overall quality and composition. Eur. Food Res. Technol. 228:671-677.

IOC. (2006). Quality Management Guide for the Olive Oil Industry: Mills.

IOC. (2014). World Olive Oil Figures. Available from http://www.interna tionaloliveoil.org/estaticos/view/131-world-olive-oil-figures

IUBMB. (2015). Recommendations on Biochemical \& Organic Nomenclature, Symbols \& Terminology. Available from http://www.chem.qmul. ac.uk/iubmb/

Jimenez, A., Rodriguez, R., Fernandez-Caro, I., Guillen, R., Fernandez-Bolanos, J. and Heredia, A. (2001). Olive fruit cell wall: Degradation of pectic polysaccharides during ripening. J. Agric. Food Chem. 49:409-415.

Kalogeropoulos, N., Kaliora, A. C., Artemiou, A. and Giogios, I. (2014). Composition, volatile profiles and functional properties of virgin olive oils produced by two-phase vs. three-phase centrifugal decanters. $L W T$ - Food Sci. Technol. 58:272-279.

Kalua, C. M., Bedgood, D. R., Bishop, A. G. and Prenzler, P. D. (2006). Changes in volatile and phenolic compounds with malaxation time and temperature during virgin olive oil production. J. Agric. Food Chem. 54:7641-7651.

Kalua, C. M., Bedgood, D. R., Bishop, A. G. and Prenzler, P. D. (2008). Changes in virgin olive oil quality during low-temperature fruit storage. J. Agric. Food Chem. 56:2415-2422.

Kashyap, D. R., Vohra, P. K., Chopra, S. and Tewari, R. (2001). Applications of pectinases in the commercial sector: A review. Bioresour. Technol. 77:215-227.

Kochevenko, A., Araújo, W. L., Maloney, G. S., Tieman, D. M., Do, P. T., Taylor, M. G., Klee, H. J. and Fernie, A. R. (2012). Catabolism of branched chain amino acids supports respiration but not volatile synthesis in tomato fruits. Molecular Plant. 5:366-375.

Koidis, A. and Boskou, D. (2006). The contents of proteins and phospholipids in cloudy (veiled) virgin olive oils. Eur. J. Lipid Sci. Technol. 108:323-328

Laane, C., Bruggeman, Y. and Winkel, C. (2003). Applications of oxireductases in foods. In: Handbook of Food Enzymology. Whitaker, J. R., Voragen, A. G. J. and Wong, D. W. S., Eds., Marcel Dekker, Inc., New York.

Lavelli, V. and Bondesan, L. (2005). Secoiridoids, tocopherols, and antioxidant activity of monovarietal extra virgin olive oils extracted from destoned fruits. J. Agric. Food Chem. 53:1102-1107.

Lercker, G., Frega, N., Bocci, F. and Servidio, G. (1994). "Veiled" extra-virgin olive oils: Dispersion response related to oil quality. J. Am. Oil Chem. Soc. 71:657-658.

López- Villalta, L. C. (2008). Obtención del aceite de oliva virgen, 3rd ed. Editorial Agricola Española, S.A., Madrid.

Lorenzi, V., Maury, J., Casanova, J. and Berti, L. (2006). Purification, product characterization and kinetic properties of lipoxygenase from olive fruit (Olea europaea L.). Plant Physiol. Biochem. 44:450-454.

Lozano-Sánchez, J., Cerretani, L., Bendini, A., Segura-Carretero, A. and Fernández-Gutiérrez, A. (2010). Filtration process of extra virgin olive oil: Effect on minor components, oxidative stability and sensorial and physicochemical characteristics. Trend Food Sci. Technol. 21: 201-211.

Luaces, P., Perez, A. G. and Sanz, C. (2003). Role of olive seed in the biogenesis of virgin olive oil aroma. J. Agric. Food Chem. 51:4741-4745.

Luaces, P., Romero, C., Gutierrez, F., Sanz, C. and Perez, A. G. (2007a). Contribution of olive seed to the phenolic profile and related quality parameters of virgin olive oil. J. S. Food Agric. 87:2721-2727.

Luaces, P., Sanz, C. and Pérez, A. G. (2007b). Thermal stability of lipoxygenase and hydroperoxide lyase from olive fruit and repercussion on olive oil aroma biosynthesis. J. Agric. Food Chem. 55:6309-6313.

Luna, G., Morales, M. T. and Aparicio, R. (2006). Characterisation of 39 varietal virgin olive oils by their volatile compositions. Food Chem. 98:243-252.

Malheiro, R., Casal, S., Teixeira, H., Bento, A. and Pereira, J. A. (2013). Effect of olive leaves addition during the extraction process of overmature fruits on olive oil quality. Food Bioproc. Technol. 6:509-521.

Martins, L. L., Reis, R., Moreira, I., Pinto, F., Sales, J. and Mourato, M. (2013). Antioxidative response of plants to oxidative stress induced by cadmium. In: Cadmium: Characteristics, Sources of Exposure, Health and Environmental Effects. Fujita, M. H. M., Ed., Nova Science Publishers, Inc.

Masella, P., Parenti, A., Spugnoli, P. and Calamai, L. (2009). Influence of vertical centrifugation on extra virgin olive oil quality. J. Am. Oil Chem. Soc. 86:1137-1140.

Masella, P., Parenti, A., Spugnoli, P. and Calamai, L. (2010). Nitrogen stripping to remove dissolved oxygen from extra virgin olive oil. Eur. J. Lipid Sci. Technol. 112:1389-1392.

Masella, P., Parenti, A., Spugnoli, P. and Calamai, L. (2012). Vertical centrifugation of virgin olive oil under inert gas. Eur. J. Lipid Sci. Technol. 114:1094-1096.

Mayer, A. M. (1986). Polyphenol oxidases in plants-recent progress. Phytochemistry. 26:11-20.

Mazzuca, S., Spadafora, A. and Innocenti, A. M. (2006). Cell and tissue localization of [beta]-glucosidase during the ripening of olive fruit (Olea europaea) by in situ activity assay. Plant Sci. 171:726-733. 
Mínguez-Mosquera, I., Gallardo-Guerrero, L. and Roca, M. (2002). Pectinesterase and polygalacturonase in changes of pectic matter in olives (cv. Hojiblanca) intended for milling. J. Am. Oil Chem. Soc. 79:93-99.

Minic, Z. (2008). Physiological roles of plant glycoside hydrolases. Planta. 227:723-740.

Minic, Z. and Jouanin, L. (2006). Plant glycoside hydrolases involved in cell wall polysaccharide degradation. Plant Physiol. Biochem. 44:435-449.

Morales, M. and Aparicio, R. (1999). Effect of extraction conditions on sensory quality of virgin olive oil. J. Am. Oil Chem. Soc. 76:295-300.

Morales, M. T., Alonso, M. V., Rios, J. J. and Aparicio, R. (1995). Virgin olive oil aroma: Relationship between volatile compounds and sensory attributes by chemometrics. J. Agric. Food Chem. 43:2925-2931.

Morales, M. T., Angerosa, F. and Aparicio, R. (1999). Effect of the extraction conditions of virgin olive oil on the lipoxygenase cascade: Chemical and sensory implications. Grasas Y Aceites. 50:114-121.

Morales, M. T., Luna, G. and Aparicio, R. (2005). Comparative study of virgin olive oil sensory defects. Food Chem. 91:293-301.

Morales, M. T., Rios, J. J. and Aparicio, R. (1997). Changes in the volatile composition of virgin olive oil during oxidation: Flavors and off-Flavors. J. Agric. Food Chem. 45:2666-2673.

Morelló, J.-R., Motilva, M.-J., Tovar, M.-J. and Romero, M.-P. (2004). Changes in commercial virgin olive oil (cv Arbequina) during storage, with special emphasis on the phenolic fraction. Food Chem. 85:357-364.

Morelló, J. R., Romero, M. P. and Motilva, M. J. (2006). Influence of seasonal conditions on the composition and quality parameters of monovarietal virgin olive oils. J. Am. Oil Chem. Soc. 83:683-690.

Mourato, M., Reis, R. and Martins, L. L. (2012). Characterization of plant antioxidative system in response to abiotic stresses: A focus on heavy metal toxicity. In: Advances in Selected Plant Physiology Aspects, p. 388. Dichio, G. M. a. B., Ed., InTech.

Moya, M., Espínola, F., Fernández, D. G., Torres, A., Marcos, J., Vilar, J., Josue, J., Sánchez, T. and Castro, E. (2010). Industrial trials on coadjuvants for olive oil extraction. J. Food Eng. 97:57-63.

Mulinacci, N., Giaccherini, C., Innocenti, M., Romani, A., Vincieri, F. F., Marotta, F. and Mattei, A. (2005). Analysis of extra virgin olive oils from stoned olives. J. Sci. Food Agric. 85:662-670.

Najafian, L., Ghodsvali, A., Haddad Khodaparast, M. H. and Diosady, L. L. (2009). Aqueous extraction of virgin olive oil using industrial enzymes. Food Res. Int. 42:171-175.

Obied, H. K., Prenzler, P. D., Ryan, D., Servili, M., Taticchi, A., Esposto, S. and Robards, K. (2008). Biosynthesis and biotransformations of phenol-conjugated oleosidic secoiridoids from Olea europaea L. Nat. Prod. Rep. 25:1167-1179.

Olias, J. M., Perez, A. G., Rios, J. J. and Sanz, L. C. (1993). Aroma of virgin olive oil: Biogenesis of the "green" odor notes. J. Agric. Food Chem. 41:2368-2373.

Ortega-Garcia, F., Blanco, S., Peinado, M. A. and Peragon, J. (2008). Polyphenol oxidase and its relationship with oleuropein concentration in fruits and leaves of olive (Olea europaea) cv. 'Picual' trees during fruit ripening. Tree Physiol. 28:45-54.

Ortega-García, F. and Peragón, J. (2010). HPLC analysis of oleuropein, hydroxytyrosol, and tyrosol in stems and roots of Olea europaea L. cv. Picual during ripening. J. Sci. Food Agric. 90:2295-2300.

Padilla, M. N., Hernaández, M. L., Sanz, C. and Martínez-Rivas, J. M. (2009). Functional characterization of two 13-Lipoxygenase genes from olive fruit in relation to the biosynthesis of volatile compounds of virgin olive oil. J. Agric. Food Chem. 57:9097-9107.

Panzanaro, S., Nutricati, E., Miceli, A. and De Bellis, L. (2010). Biochemical characterization of a lipase from olive fruit (Olea europaea L.). Plant Physiol. Biochem. 48:741-745.

Parenti, A., Spugnoli, P., Masella, P. and Calamai, L. (2007). Influence of the extraction process on dissolved oxygen in olive oil. Eur. J. Lipid Sci. Technol. 109:1180-1185.

Parenti, A., Spugnoli, P., Masella, P. and Calamai, L. (2008). The effect of malaxation temperature on the virgin olive oil phenolic profile under laboratory-scale conditions. Eur. J. Lipid Sci. Technol. 110:735-741.

Parenti, A., Spugnoli, P., Masella, P., Calamai, L. and Pantani, O. L. (2006). Improving olive oil quality using $\mathrm{CO} 2$ evolved from olive pastes during processing. Eur. J. Lipid Sci. Technol. 108:904-912.
Pastore, G., D'Aloise, A., Lucchetti, S., Maldini, M., Moneta, E., Peparaio M., Raffo, A. and Sinesio, F. (2014). Effect of oxygen reduction during malaxation on the quality of extra virgin olive oil (Cv. Carboncella) extracted through "two-phase" and "three-phase" centrifugal decanters. LWT - Food Sci. Technol. 59:163-172.

Pereira, J. A., Casal, S., Bento, A. and Oliveira, M. B. P. P. (2002). Influence of olive storage period on oil quality of three portuguese cultivars of Olea europea, Cobrançosa, Madural, and Verdeal Transmontana. J. Agric. Food Chem. 50:6335-6340.

Peres, F., Jeleń, H. H., Majcher, M. M., Arraias, M., Martins, L. L. and Ferreira-Dias, S. (2013a). Characterization of aroma compounds in Portuguese extra virgin olive oils from Galega Vulgar and Cobrançosa cultivars using GC-O and GCxGC-ToFMS. Food Res. Int. 54:19791986.

Peres, F., Martins, L. L. and Ferreira-Dias, S. (2014). Laboratory-scale optimization of olive oil extraction: Simultaneous addition of enzymes and microtalc improves the yield. Eur. J. Lipid Sci. Technol. 116:1054-1062.

Peres, F., Martins, L. L., Mourato, M. and Ferreira-Dias, S. (2011). Changes in virgin olive oil antioxidants, polyphenol oxidase and peroxidase activities during fruit ripening. In: 4th International Conference Olivebioteq 2011, Chania, pp. 515-520.

Peres, F., Martins, L. L., Mourato, M. and Ferreira-Dias, S. (2013b). The role of polyphenol oxidases and peroxidases from olive fruits on the composition of virgin oil. In: EUROFOODCHEM XVII, Istanbul, pp. 722.

Perez, A. G., Leon, L., Pascual, M., Romero-Segura, C., Sanchez-Ortiz, A., de la Rosa, R. and Sanz, C. (2014). Variability of virgin olive oil phenolic compounds in a segregating progeny from a single cross in Olea europaea L. and sensory and nutritional quality implications. Plos One. 9.

Pérez, A. G., Luaces, P., Ríos, J. J., García, J. M. and Sanz, C. (2003). Modification of volatile compound profile of virgin olive oil due to hot-water treatment of olive fruit. J. Agric. Food Chem. 51:6544-6549.

Pérez, A. G., Romero, C., Yousfi, K. and García, J. (2008). Modulation of olive oil quality using $\mathrm{NaCl}$ as extraction coadjuvant. J. Am. Oil Chem. Soc. 85:685-691.

Perez-Camino, M. C., Moreda, W. and Cert, A. (2001). Effects of olive fruit quality and oil storage practices on the diacylglycerol content of virgin olive oils. J. Agric. Food Chem. 49:699-704.

Peri, C. (2014). Quality excellence in extra virgin olive oils. In: Olive Oil Sensory Science, pp. 1-32. Monteleone, E. a. S. L., Ed., John Wiley \& Sons, Ltd., New York.

Petrakis, C. (2006). Olive Oil Extraction. In: Olive Oil Chemistry \& Technology, 2nd ed., pp. 191-224. Boskou, D., Ed., AOCS Press, Champaign, Illinois.

Pita, D., Vitorino, M. C., Gouveia, C. and Peres, F. (2011). Aplicação de Microtalco Natural na Extracção de Azeites Monovarietais (The use of natural microtalc in the extraction of monocultivar olive oils). Actas Portuguesas de Horticultura 151-155.

Prasanna, V., Prabha, T. N. and Tharanathan, R. N. (2007). Fruit ripening phenomena-An overview. Crit. Rev. Food Sci. Nutr. 47:1-19.

Prenzler, P., Robards, K. and Bedgood, D. (2007). Quality Enhancement of Australian Extra Virgin Olive Oils, p. 116. Rural Industries Research and Development Corporation.

Psomiadou, E. and Tsimidou, M. (2002). Stability of virgin olive oil. 2. Photo-oxidation studies. J. Agric. Food Chem. 50:722-727.

Ramírez, E. C., Whitaker, J. R. and Virador, V. M. (2003). Polyphenol Oxidase. In: Handbook of Food Enzymology. Whitaker, J. R., Voragen, A. G. J. and Wong, D. W. S., Eds., Marcel Dekker, Inc., New York.

Ranalli, A., Contento, S., Schiavone, C. and Simone, N. (2001a). Malaxing temperature affects volatile and phenol composition as well as other analytical features of virgin olive oil. Eur. J. Lipid Sci. Technol. 103:228-238.

Ranalli, A. and De Mattia, G. (1997). Characterization of olive oil produced with a new enzyme processing aid. J. Am. Oil Chem. Soc. 74:1105-1113.

Ranalli, A., De Mattia, G. and Ferrante, M. L. (1998). The characteristics of percolation olive oils produced with a new processing enzyme aid. Int. J. Food Sci. Technol. 33:247-258.

Ranalli, A. and Ferrante, M. L. (1996). Las características fisicoquímicas y analíticas de los aceites virgenes extraídos mediante un auxiliar 
enzimático pectolítico (Physicochemical and analytical properties of virgin olive oils extracted with a pectolytic enzyme adjuvant). Olivae. 60:27-32.

Ranalli, A., Gomes, T., Delcuratolo, D., Contento, S. and Lucera, L. (2003a). Improving virgin olive oil quality by means of innovative extracting biotechnologies. J. Agric. Food Chem. 51:2597-2602.

Ranalli, A., Lucera, L., Contento, S., Simone, N. and Del Re, P. (2004). Bioactive constituents, flavors and aromas of virgin oils obtained by processing olives with a natural enzyme extract. Eur. J. Lipid Sci. Technol. 106:187-197.

Ranalli, A., Malfatti, A. and Cabras, P. (2001b). Composition and quality of pressed virgin olive oils extracted with a new enzyme processing aid. $J$. Food Sci. 66:592-603.

Ranalli, A., Malfatti, A., Lucera, L., Contento, S. and Sotiriou, E. (2005). Effects of processing techniques on the natural colourings and the other functional constituents in virgin olive oil. Food Res. Int. 873-878.

Ranalli, A. and Martinelli, N. (1995). Integral centrifuges for olive oil extraction, at the third millenium threshold. Transformation yields. Grasas Y Aceites. 46:255-263.

Ranalli, A., Pollastri, L., Contento, S. and Iannucci, E. (2003b). The glyceridic and nonglyceridic constituents of virgin olive oil after use of a novel method of enzyme extraction. Int. J. Food Sci. Technol. 38:17-27.

Ranalli, A., Pollastri, L., Contento, S., Iannucci, E. and Lucera, L. (2003c). Effect of olive paste kneading process time on the overall quality of virgin olive oil. Eur. J. Lipid Sci. Technol. 105:57-67.

Ranalli, A., Sgaramella, A. and Surricchio, G. (1999). The new "Cytolase 0" enzyme processing aid improves quality and yields of virgin olive oil. Food Chem. 66:443-454.

Reboredo-Rodríguez, P., González-Barreiro, C., Cancho-Grande, B. and Simal-Gándara, J. (2013). Effects of sedimentation plus racking process in the extra virgin olive oil aroma fingerprint obtained by DHS-TD/ GC-MS. Food Bioproc. Technol. 6:1290-1301.

Reboredo-Rodríguez, P., González-Barreiro, C., Cancho-Grande, B. and Simal-Gándara, J. (2014). Improvements in the malaxation process to enhance the aroma quality of extra virgin olive oils. Food Chem. 158:534-545.

Ridolfi, M., Terenziani, S., Patumi, M. and Fontanazza, G. (2002). Characterization of the lipoxygenases in some olive cultivars and determination of their role in volatile compounds formation. J. Agric. Food Chem. 50:835-839.

Rodis, P. S., Karathanos, V. T. and Mantzavinou, A. (2002). Partitioning of olive oil antioxidants between oil and water phases. J. Agric. Food Chem. 50:596-601.

Rojnić, I. D., Bažok, R. and Barčić, J. I. (2015). Reduction of olive fruit fly damage by early harvesting and impact on oil quality parameters. Eur. J. Lipid Sci. Technol. 117:103-111.

Romero-Segura, C., García-Rodríguez, R., Sánchez-Ortiz, A., Sanz, C. and Pérez, A. G. (2012). The role of olive $\beta$-glucosidase in shaping the phenolic profile of virgin olive oil. Food Res. Int. 45:191-196.

Romero-Segura, C., Sanz, C. and Perez, A. G. (2009). Purification and characterization of an olive fruit $\beta$-Glucosidase involved in the biosynthesis of virgin olive oil phenolics. J. Agric. Food Chem. 57:79837988.

Runcio, A., Sorgonà, L., Mincione, A., Santacaterina, S. and Poiana, M. (2008). Volatile compounds of virgin olive oil obtained from Italian cultivars grown in Calabria. Effect of processing methods, cultivar, stone removal, and antracnose attack. Food Chem. 106:735-740.

Ryan, D., Robards, K. and Lavee, S. (1999). Changes in phenolic content of olive during maturation. Int. J. Food Sci. Technol. 34:265-274.

Salas, J., Willams, M., Harwood, J. and Sánchez, J. (1999). Lipoxygenase activity in olive (Olea europaea) fruit. J. Am. Oil Chem. Soc. 76:11631168.

Salas, J. J. (2004). Characterization of alcohol acyltransferase from olive fruit. J. Agric. Food Chem. 52:3155-3158.

Salas, J. J., Sanchez, C., Garcia-Gonzalez, D. L. and Aparicio, R. (2005). Impact of the suppression of lipoxygenase and hydroperoxide lyase on the quality of the green odor in green leaves. J. Agric. Food Chem. 53:1648-1655.
Salas, J. J. and Sánchez, J. (1999). Hydroperoxide lyase from olive (Olea europaea) fruits. Plant Sci. 143:19-26.

Salas, J. J., Sánchez, J., Ramli, U. S., Manaf, A. M., Williams, M. and Harwood, J. L. (2000). Biochemistry of lipid metabolism in olive and other oil fruits. Prog. Lipid Res. 39:151-180.

Sánchez, J. and Harwood, J. L. (2002). Biosynthesis of triacylglycerols and volatiles in olives. Eur. J. Lipid Sci. Technol. 104:564-573.0..

Sánchez-Ortiz, A., Pérez, A. G. and Sanz, C. (2007). Cultivar differences on nonesterified polyunsaturated fatty acid as a limiting factor for the biogenesis of virgin olive oil aroma. J. Agric. Food Chem. 55:7869-7873.

Sánchez-Ortiz, A., Pérez, A. G. and Sanz, C. (2013). Synthesis of aroma compounds of virgin olive oil: Significance of the cleavage of polyunsaturated fatty acid hydroperoxides during the oil extraction process. Food Res. Int. 54:1972-1978.

Sánchez-Ortiz, A., Romero-Segura, C., Sanz, C. and Pérez, A. G. (2011). Synthesis of volatile compounds of virgin olive oil is limited by the lipoxygenase activity load during the oil extraction process. J. Agric. Food Chem. 60:812-822.

Saraiva, J. A., Nunes, C. S. and Coimbra, M. A. (2007). Purification and characterization of olive (Olea europaea L.) peroxidase - Evidence for the occurrence of a pectin binding peroxidase. Food Chem. 101:15711579.

Sciancalepore, V. (1985). Enzymatic browning in five olive varieties. $J$. Food Sci. 50:1194-1195.

Segovia-Bravo, K. A., Jarén-Galán, M., García-García, P. and GarridoFernández, A. (2009). Browning reactions in olives: Mechanism and polyphenols involved. Food Chem. 114:1380-1385.

Selvaggini, R., Esposto, S., Taticchi, A., Urbani, S., Veneziani, G., Di Maio, I., Sordini, B. and Servili, M. (2014). Optimization of the temperature and oxygen concentration conditions in the malaxation during the oil mechanical extraction process of four Italian olive cultivars. J. Agric. Food Chem. 62:3813-3822.

Servili, M. (2014). The phenolic compounds: A commercial argument in the economic war to come on the quality of olive oil?. OCL. 21: D509.

Servili, M., Baldioli, M., Begliomini, A. L., Selvaggini, R. and Montedoro, G. F. (2000). The phenolic and volatile compounds of virgin olive oil: Relationships with the endogenous oxidorreductases during the mechanical oil extraction process. In: Flavour and Fragrance Chemistry, pp. 163-173. Lanzotti, V. and Taglialatela-Scafati, O., Eds., Kluwer Academic Publishers, Dordrecht.

Servili, M., Begliomini, A. L., Montedoro, G. F., Petruccioli, M. and Federici, F. (1992). Utilisation of a yeast pectinase in olive oil extraction and red wine making processes. J. Sci. Food Agric. 58:253-260.

Servili, M., Esposto, S., Fabiani, R., Urbani, S., Taticchi, A., Mariucci, F., Selvaggini, R. and Montedoro, G. (2009). Phenolic compounds in olive oil: Antioxidant, health and organoleptic activities according to their chemical structure. Inflammopharmacology. 17:76-84.

Servili, M., Piacquadio, P., De Stefano, G., Taticchi, A. and Sciancalepore, V. (2002a). Influence of a new crushing technique on the composition of the volatile compounds and related sensory quality of virgin olive oil. Eur. J. Lipid Sci. Technol. 104:483-489.

Servili, M., Selvaggini, R., Esposto, S., Taticchia, A., Montedoro, G. F. and Morozzib, G. (2004). Health and sensory properties of virgin olive oil hydrophilic phenols: Agronomic and technological aspects of production that affect their occurrence in the oil. J. Chromatogr. A 1054: 113-127.

Servili, M., Selvaggini, R., Taticchi, A., Baldioli, M. and Montedoro, G. F. (2002b). The use of biotechnology means during oil mechanical extraction process: Relationship with sensory and nutritional parameters of virgin olive oil. Acta Horticulturae 557-560.

Servili, M., Selvaggini, R., Taticchi, A., Esposto, S. and Montedoro, G. (2003a). Air exposure time of olive pastes during the extraction process and phenolic and volatile composition of virgin olive oil. J. Am. Oil Chem. Soc. 80:685-695.

Servili, M., Selvaggini, R., Taticchi, A., Esposto, S. and Montedoro, G. F. (2003b). Volatile compounds and phenolic composition of virgin olive oil: Optimization of temperature and time of exposure of olive pastes to air contact during the mechanical extraction. J. Agric. Food Chem. 51:7980-7988. 
Servili, M., Taticchi, A., Esposto, S., Sordini, B. and Urbani, S. (2012). Technological aspects of olive oil production. In: Olive Germplasm The Olive Cultivation, Table Olive and Olive Oil Industry in Italy. Available from http://www.intechopen.com/books/olive-germplasmthe- olive-cultivation-table-olive-and-olive-oil-industry-in-italy/techno logical- aspects-of-olive-oil-production

Servili, M., Taticchi, A., Esposto, S., Urbani, S., Selvaggini, R. and Montedoro, G. (2007). Effect of olives on the volatile and phenolic composition of virgin olive oil. J. Agric. Food Chem. 55:7028-7035.

Servili, M., Taticchi, A., Esposto, S., Urbani, S., Selvaggini, R. and Montedoro, G. F. (2008). Influence of the decrease in oxygen during malaxation of olive paste on the composition of volatiles and phenolic compounds in virgin olive oil. J. Agric. Food Chem. 56:10048-10055.

Sonda, A., Akram, Z., Boutheina, G., Guido, F. and Mohamed, B. (2013). Effect of addition of olive leaves before fruits extraction process to some monovarietal Tunisian extra-virgin olive oils using chemometric analysis. J. Agric. Food Chem. 62:251-263.

Spadafora, A., Mazzuca, S., Chiappetta, F. F., Parise, A., Perri, E. and Innocenti, A. M. (2008). Oleuropein-specific-[beta]-glucosidase activity marks the early response of olive Fruits (Olea europaea) to mimed insect attack. Agric. Sci. China. 7:703-712.

Stefanoudaki, E., Koutsaftakis, A. and Harwood, J. L. (2011). Influence of malaxation conditions on characteristic qualities of olive oil. Food Chem. 127:1481-1486.

Stefanoudaki, E., Williams, M. and Harwood, J. (2010). Changes in virgin olive oil characteristics during different storage conditions. Eur. J. Lipid Sci. Technol. 112:906-914.

Takahama, U. and Oniki, T. (2000). Flavonoids and some other phenolics as substrates of peroxidase: Physiological significance of the redox reactions. J. Plant Res. 113:301-309.

Taticchi, A., Esposto, S. and Servili, M. (2014). The Basis of the Sensory Properties of Virgin Olive Oil. In: Olive Oil Sensory Science, pp. 3354. Monteleone, E. a. S. L., Ed., John Wiley \& Sons, Ltd., New York.

Taticchi, A., Esposto, S., Veneziani, G., Urbani, S., Selvaggini, R. and Servili, M. (2013). The influence of the malaxation temperature on the activity of polyphenoloxidase and peroxidase and on the phenolic composition of virgin olive oil. Food Chem. 136:975-983.

Tena, N., Lazzez, A., Aparicio-Ruiz, R. and García-González, D. L. (2007). Volatile compounds characterizing Tunisian Chemlali and Chétoui virgin olive oils. J. Agric. Food Chem. 55:7852-7858.

Tomás-Barberán, F. A. and Espín, J. C. (2001). Phenolic compounds and related enzymes as determinants of quality in fruits and vegetables. $J$. Sci. Food Agric. 81:853-876.

Trichopoulou, A. and Dilis, V. (2007). Olive oil and longevity. Mol. Nutr. Food Res. 51:1275-1278.

Tsimidou, M. Z., Georgiou, A., Koidis, A. and Boskou, D. (2005). Loss of stability of "veiled" (cloudy) virgin olive oils in storage. Food Chem. 93:377-383.

Tura, D., Failla, O., Bassi, D., Attilio, C. and Serraiocco, A. (2013). Regional and cultivar comparison of Italian single cultivar olive oils according to flavor profiling. Eur. J. Lipid Sci. Technol. 115:196-210.

Tura, D., Failla, O., Bassi, D., Ped f, S. and Serraiocco, A. (2008). Cultivar influence on virgin olive (Olea europea L.) oil flavor based on aromatic compounds and sensorial profile. Scientia Horticulturae. 118:139-148.

Tura, D., Failla, O., Bassi, D., Ped $\int$, S. and Serraiocco, A. (2009). Environmental and seasonal influence on virgin olive (Olea europaea L.) oil volatiles in northern Italy. Scientia Horticulturae. 122:385-392.

Tzika, E. D., Sotiroudis, T., Papadimitriou, V. and Xenakis, A. (2009). Partial purification and characterization of peroxidase from olives (Olea europaea cv. Koroneiki). Eur. Food Res. Technol. 228:487-495.

Uceda, M., Jimenez, A. and Beltran, G. (2006). Olive oil extraction and quality. Grasas Y Aceites. 57:25-31.

Vámos -Vigyázó, L. and Haard, N. F. (1981). Polyphenol oxidases and peroxidases in fruits and vegetables. Crit. Rev. Food Sci. Nutr. 15:49-127.

Vaughn, K. C. and Duke, S. O. (1981). Tissue localization of polyphenol oxidase in Sorghum. Protoplasma. 108:319-327.
Veillet, S., Tomao, V., Bornard, I., Ruiz, K. and Chemat, F. (2009). Chemical changes in virgin olive oils as a function of crushing systems: Stone mill and hammer crusher. Comptes Rendus Chimie. 12:895-904.

Vergara-Domínguez, H., Roca, M. and Gandul-Rojas, B. (2013). Characterisation of chlorophyll oxidation mediated by peroxidative activity in olives (Olea europaea L.) cv. Hojiblanca. Food Chem. 139: 786-795.

Vichi, S., Castellote, A. I., Pizzale, L., Conte, L. S., Buxaderas, S. and LópezTamames, E. (2003). Analysis of virgin olive oil volatile compounds by headspace solid-phase microextraction coupled to gas chromatography with mass spectrometric and flame ionization detection. J. Chromatogr. A 983:19-33.

Vichi, S., Romero, A., Gallardo-Chacón, J., Tous, J., López-Tamames, E. and Buxaderas, S. (2009a). Volatile phenols in virgin olive oils: Influence of olive variety on their formation during fruits storage. Food Chem. 116:651-656.

Vichi, S., Romero, A., Gallardo-Chacoán, J., Tous, J., Loápez-Tamames, E. and Buxaderas, S. (2009b). Influence of olives' storage conditions on the formation of volatile phenols and their role in off-odor formation in the oil. J. Agric. Food Chem. 57:1449-1455.

Vichi, S., Romero, A., Tous, J. and Caixach, J. (2011). The activity of healthy olive microbiota during virgin olive oil extraction influences oil chemical composition. J. Agric. Food Chem. 59:4705-4714.

Vichi, S., Romero, A., Tous, J., Tamames, E. L. and Buxaderas, S. (2008). Determination of volatile phenols in virgin olive oils and their sensory significance. J. Chromatogr. A 1211:1-7.

Vierhuis, E., Korver, M., Schols, H. A. and Voragen, A. G. J. (2003). Structural characteristics of pectic polysaccharides from olive fruit (Olea europaea $\mathrm{cv}$ moraiolo) in relation to processing for oil extraction. Carbohydr. Polymers. 51:135-148.

Vierhuis, E., Schols, H. A., Beldman, G. and Voragen, A. G. J. (2000). Isolation and characterisation of cell wall material from olive fruit (Olea europaea cv. koroneiki) at different ripening stages. Carbohydr. Polymers. 43:11-12.

Vierhuis, E., Servili, M., Baldioli, M., Schols, H. A., Voragen, A. G. J. and Montedoro, G. F. (2001). Effect of enzyme treatment during mechanical extraction of olive oil on phenolic compounds and polysaccharides. J. Agric. Food Chem. 49:1218-1223.

Vinha, A. F., Ferreres, F., Silva, B. M., Valentão, P., Gonçalves, A., Pereira, J. A., Oliveira, M. B. P., Seabra, R. M. and Andrade, P. B. (2005). Phenolic profiles of Portuguese olive fruits (Olea europaea L.): Influences of cultivar and geographical origin. Food Chem. 89:561-568.

Whitaker, J. R. (1995). Polyphenol Oxidase. In: Food Enzymes, pp. 271-307. Springer US, New York.

Whitaker, J. R. (2003). What enzymes do and why they are highly specific and efficient catalysts. In: Handbook of Food Enzymology. Whitaker, J. R., Voragen, A. G. J. and Wong, D. W. S., Eds., Marcel Dekker, Inc. New York.

Williams, M. and Harwood, J. L. (2000). Characterization of lipoxygenase isoforms in olive callus cultures. Biochem. Soc. Trans. 28:830-831.

Yoruk, R. and Marshal, R. (2003). Physicochemical properties and function of plant polyphenol oxidase: A review. J. Food Biochem. 27:361-422.

Yorulmaz, A., Tekin, A. and Turan, S. (2011). Improving olive oil quality with double protection: Destoning and malaxation in nitrogen atmosphere. Eur. J. Lipid Sci. Technol. 113:637-643.

Yuan, Z. Y. and Jiang, T. J. (2003). Horseradish Peroxidase. In: Handbook of Food Enzymology. Whitaker, J. R., Voragen, A. G. J. and Wong, D. W. S., Eds., Marcel Dekker, Inc., New York.

Zamora, R., Alaiz, M. and Hidalgo, F. J. (2002). Influence of cultivar and fruit ripening on olive (Olea europaea) fruit protein content, composition and antioxidant activity. J. Agric. Food Chem. 49:4267-4270.

Zullo, B. A., Di Stefano, M. G., Cioccia, G. and Ciafardini, G. (2014). Evaluation of polyphenol decay in the oily fraction of olive fruit during storage using a mild sample handling method. Eur. J. Lipid Sci. Technol. 116:160-168 